\title{
Functional anatomy of the gibbon forelimb: adaptations to a brachiating lifestyle
}

\author{
Fana Michilsens, ${ }^{1,2}$ Evie E. Vereecke, ${ }^{1,3}$ Kristiaan D'Août ${ }^{1,2}$ and Peter Aerts ${ }^{1,4}$ \\ ${ }^{1}$ Laboratory for Functional Morphology, University of Antwerp, Belgium \\ ${ }^{2}$ Centre for Research and Conservation, Royal Zoological Society of Antwerp, Belgium \\ ${ }^{3}$ Department of Human Anatomy and Cell Biology, School of Biomedical Sciences, University of Liverpool, UK \\ ${ }^{4}$ Department of Movement and Sport Sciences, University of Ghent, Belgium
}

\begin{abstract}
It has been shown that gibbons are able to brachiate with very low mechanical costs. The conversion of muscle activity into smooth, purposeful movement of the limb depends on the morphometry of muscles and their mechanical action on the skeleton. Despite the gibbon's reputation for excellence in brachiation, little information is available regarding either its gross musculoskeletal anatomy or its more detailed muscle-tendon architecture. We provide quantitative anatomical data on the muscle-tendon architecture (muscle mass, physiological cross-sectional area, fascicle length and tendon length) of the forelimb of four gibbon species, collected by detailed dissections of unfixed cadavers. Data are compared between different gibbon species and with similar published data of nonbrachiating primates such as macaques, chimpanzees and humans. No quantitative differences are found between the studied gibbon species. Both their forelimb anatomy and muscle dimensions are comparable when normalized to the same body mass. Gibbons have shoulder flexors, extensors, rotator muscles and elbow flexors with a high power or work-generating capacity and their wrist flexors have a high force-generating capacity. Compared with other primates, the elbow flexors of gibbons are particularly powerful, suggesting that these muscles are particularly important for a brachiating lifestyle. Based on this anatomical study, the shoulder flexors, extensors, rotator muscles, elbow flexors and wrist flexors are expected to contribute the most to brachiation.
\end{abstract}

Key words anatomy; biomechanics; brachiation; Hylobates; muscle architecture.

\section{Introduction}

Gibbons and siamangs (Fam. Hylobatidae) are skilled brachiators and are known for the dominant use of this locomotor mode during travelling (50-80\% of their travelling time) (Fleagle, 1974, 1976; Andrews \& Groves, 1976; Carpenter, 1976; Hollihn, 1984; Preuschoft \& Demes, 1984; Tuttle, 1986; Takahashi, 1990). The definition of brachiation given by Hollihn (1984) is widely accepted and states that brachiation is 'bimanual progression along or between overhead structures for a distance of several metres without the intermittent use of other types of positional behaviour and without support by the hind limbs or tail'. According to this definition, the hylobatids are the only true brachiators. Although some work has been done on the anatomical characteristics of brachiators (Tuttle, 1972; Schultz, 1973;

\section{Correspondence}

Fana Michilsens, Laboratory for Functional Morphology, University

of Antwerp, CDE - Universiteitsplein 1-2610 Wilrijk, Belgium.

E: fana.michilsens@ua.ac.be

Accepted for publication 15 May 2009
Andrews \& Groves, 1976; Fleagle, 1979, 1999; Hollihn, 1984; Swartz et al. 1989; Takahashi, 1990; Chan, 2007) and the mechanics of brachiation (Fleagle, 1976; Chang et al. 1997; Bertram et al. 1999; Chang et al. 2000; Bertram \& Chang, 2001; Usherwood et al. 2003; Gomes \& Ruina, 2005), these studies almost never engaged in extensively linking anatomical findings to observed movements (except some electromyographic studies of specific muscles; Stern et al. 1980; Jungers \& Stern, 1981; Susman et al. 1982; Stern \& Larson, 2001) and, to our knowledge, no study ever provided functional muscle characteristics [muscle masses, physiological cross-sectional areas (PCSAs) and fascicle lengths (FLs)] of the gibbon forelimb.

The aim of this study was therefore to quantify forelimb muscle architecture in gibbons, discuss the findings in relationship to their locomotor habits and compare them with other primates, more specifically non-brachiators (e.g. humans), semi-brachiators (e.g. Ateles) and so-called 'modified' brachiators (e.g. chimpanzees). [Napier \& Napier (1967) introduced this term to refer to a form of arboreal locomotion in which the forelimbs play a major role in suspending the body or propelling it through space; this does not make any implications about the amount of 
time spent moving around in that way or about the biomechanical adaptations towards this locomotor mode.]

Apart from providing a detailed account of the functional anatomy of the gibbon forelimb, such data are a necessary input for biomechanical modelling (inverse and forward dynamics) and computer simulations. As such, they are crucial to advance our knowledge of the biomechanics of brachiation. We do not intend to provide a detailed comparison of functional forelimb anatomy among primates or to provide an extensive interspecific comparison within gibbons. Our primary goal was to provide a general functional analysis of the gibbon forelimb. However, due to the composition of our sample (different species and genera) it was necessary to investigate if interspecific differences in musculature exist. Eventually, we are interested in the distinct anatomical features of gibbons that might help to explain their excellent brachiating skills.

Assessing an animal's functional muscular anatomy can be done by analysing four basic parameters: muscle mass, muscle PCSA, muscle FL and tendon length (TL) (Thorpe et al. 1999). The PCSA gives information about the forcegenerating capacity of the muscle because a high PCSA is associated with a large number of sarcomeres lying in parallel. The $\mathrm{FL}$, however, reflects the number of sarcomeres lying in series and is proportional to the possibility of the muscle generating force over a wider range of motion and to the shortening velocity of the muscle (it should be kept in mind that the resultant kinematics also depend on muscle fibre type and moment arm) (Thorpe et al. 1999; Payne et al. 2006). Muscles that have equal volumes will have a similar capacity for power generation, as power is force $x$ velocity and is therefore directly related to muscle volume (Zajac, 1992; Payne et al. 2006). As muscle volume is proportional to muscle mass, this parameter gives a first estimate of the power-producing capacity of a muscle. Obviously, the presence of a tendon can also have an important influence on the function of a muscle-tendon unit (MTU) (Anapol \& Gray, 2003). Muscles with long tendons, i.e. a high TL : MTU ratio, may be able to contract nearly isometrically (Biewener, 1998; Alexander 2002; Roberts, 2002), leading to a low shortening velocity of the muscle fibres and hence a high force production (due to the force-velocity relationship; Hill, 1953). In addition, long tendons might be able to store elastic strain energy that can be released in a following cycle (Alexander, 2002). A low TL : MTU ratio means that there will be an isotonic contraction in which all shortening will happen in the muscle belly itself. In this case, contraction is possible at a high speed but not at maximal force production because the muscle fibres will typically not be operating at maximal myofilament overlap (Anapol \& Gray, 2003).

The muscle characteristics mentioned above are linked with the locomotor behaviour of the animal. Previous studies have already pointed to some particular characteristics in the forelimb musculature of highly suspensory primates: large digital flexor muscles (Tuttle, 1972), a large supinator muscle (brachiating compared with non-brachiating species; Tuttle, 1972) and large lattissimus dorsi and teres major muscles (Fleagle, 1979). Thorpe et al. (1999) demonstrated that, because of their arboreal lifestyle, chimpanzees have relatively stronger elbow and wrist flexors than humans and mechanical studies of gibbon brachiation also indicated that the supporting arm is commonly flexed to hoist the body and optimize the arm-swinging movement (Fleagle, 1979; Stern et al. 1980; Jungers \& Stern, 1981; Turnquist et al. 1999; Usherwood et al. 2003; Usherwood \& Bertram, 2003). Although posture and other habits (e.g. feeding) also influence the general anatomy, it is commonly accepted that the animal's muscle anatomy is largely shaped by its locomotor mode due to the high frequency and high loads involved (and hence strong selective pressure) (Fleagle, 1979). Based on this information and knowing that gibbons are highly arboreal and brachiate for more than $50 \%$ of their active time (Fleagle, 1976), we expect that the gibbon forelimb will be characterized by elbow and wrist flexors with a high forcegenerating capacity (high PCSAs). We also expect that the wrist/digital flexors will be coupled to long tendons, enabling isometric contraction and thus maximal force production while having the opportunity to store strain energy in their tendons. The storage and release of elastic energy can contribute to smaller energy expenditure during the locomotion cycle (cf. running according to the spring-mass model in humans; Cavagna et al. 1977). The shoulder muscles, however, should be capable of acting over a wide range of motion and we therefore expect that the shoulder musculature will be characterized by long FLs. Equally important is stabilization of the shoulder joint in all possible positions and during rapid locomotion with high loads. The shoulder, as an inherently mobile joint, depends largely on the muscles and tendons for its stabilization. The muscles responsible for stabilizing the shoulder are expected to be pennate muscles that run close to the joint with short, firm tendons.

\section{Materials and methods}

\section{Subject data}

Three adult lar gibbons (Hylobates lar), two pileated gibbons (H. pileatus), two moloch gibbons (H. moloch) and four siamangs (Symphalangus syndactylus) of known age and sex were dissected (Table 1). All specimens died under natural circumstances and showed no obvious musculoskeletal pathology. Cadavers were obtained from the National Museums of Scotland, Edinburgh (NMS) and from the Royal Zoological Society of Antwerp. The specimens were eviscerated during post-mortem examination and kept frozen $\left(-18{ }^{\circ} \mathrm{C}\right)$ until required for the analysis. All dissections were conducted on unfixed material that had been defrosted at room temperature or in the fridge. The body mass of each subject was obtained prior to evisceration and was used for normalization 
Table 1 Subject data

\begin{tabular}{|c|c|c|c|c|c|c|c|c|c|c|c|}
\hline & Lar 1 & Lar 2 & Lar 3 & Pileated 1 & Pileated 2 & Moloch 1 & Moloch 2 & Siamang 1 & Siamang 2 & Siamang 3 & Siamang 4 \\
\hline Sex & $\mathrm{M}$ & $M$ & $\mathrm{~F}$ & $\mathrm{M}$ & $\mathrm{F}$ & $M$ & $M$ & $\mathrm{~F}$ & $\mathrm{~F}$ & $\mathrm{~F}$ & $\mathrm{M}$ \\
\hline $\begin{array}{l}\text { Age at } \\
\text { death (years) }\end{array}$ & 6 & 26 & 21.8 & 41 & 24.5 & 19 & Adult & 32 & 9 & 35 & Adult \\
\hline Mass (kg) & 6.3 & 10.6 & 6.5 & 5.2 & $6.7 *$ & 5.8 & $7.3^{*}$ & 12.47 & 8.5 & 11.55 & 10.1 \\
\hline Origin & Pld & Unknown & Pld & $P$ & $\mathrm{~T}$ & PL & Unknown & $A$ & $\mathrm{~T}$ & $\mathrm{~T}$ & PL \\
\hline Collection & RZSA & NMS & RZSA & NMS & NMS & NMS & NMS & RZSA & NMS & NMS & NMS \\
\hline
\end{tabular}

M, male; F, female; RZSA, Royal Zoological Society of Antwerp; NMS, National Museum of Scotland; Pld, Planckendael Animal Park, B; P, Paignton Zoo, UK; T, Twycross Zoo, UK; PL, Port Lympe, UK; A, Antwerp Zoo, B.

*Estimated values.

of data (Table 1). For Moloch 2 and Pileated 2, however, no pre-evisceration mass was available. For these specimens it was assumed that the ratio of forelimb muscle mass to total body mass was similar to that of the other specimen of the same species. For each specimen, the right forelimb was used to collect data on muscle architecture, whereas the left forelimb was left intact for further measurements.

The forelimb musculature of gibbons was compared with other primates for which data were available from the literature. For the evaluation of interspecific variation in origin and insertion, we included atelines (Youlatos, 2000) as an example of semi-brachiators, bonobos (Pan paniscus; Miller, 1952) as 'modified' brachiators and macaques (Macaca irus; Kimura \& Takai, 1970) and humans (Gray, 1918) as non-brachiators. For the comparison of muscle dimensions, we used common chimpanzees ( $P$. troglodytes; Thorpe et al. $1999)$ as an example of 'modified' brachiators and macaques (M. mulatta and M. fascicularis; Cheng \& Scott, 2000) and humans as non-brachiators (Thorpe et al. 1999).

\section{Measurement of forelimb muscle dimensions}

During the dissection of each right forelimb, muscles were removed systematically and measurements of muscle mass, MTU, muscle belly and TL were recorded, as well as the origin, insertion and inferred function of each muscle. Masses were measured with an electronic scale (Radwag, Poland) to the nearest $0.1 \mathrm{~g}$ and lengths were measured with digital calipers (Mitutoyo, Japan) to the nearest $0.01 \mathrm{~mm}$. Each muscle was then cut along the line of the tendon to determine the arrangement of muscle fascicles. Three separate measurements of muscle FL were recorded from different sections of the muscle belly and a mean value was calculated. A photograph was taken with a digital camera to determine the pennation angle, i.e. the angle between internal tendon and muscle fascicles (to improve accuracy, care was taken to place the camera lens parallel to the plane of the muscle). The TL was measured as comprising both the external and internal portion of the tendon; after this the external tendon was removed to measure the muscle belly mass. When possible, a sample of the external tendon was measured and weighed to determine the tendon cross-sectional area (TCSA) (see below). Note that the specimens obtained from NMS were skinned by a taxidermist of the NMS prior to transportation to our laboratory. As a result, the phalanges were removed and the distal parts of the tendons inserting onto the digits were cut off. The TLs and MTUs of flexor digitorum superficialis (FDS), flexor digitorum profundus (FDP), extensor digitorum communis (EDC), extensor digitorum brevis (EDB), ex- tensor digiti minimi (EDM) and extensor pollicis longus (EPL) of these specimens were therefore omitted from our calculations (see Table 2 for abbreviations of muscle names).

\section{Calculation of anatomical parameters}

The PSCA of the muscle can be estimated as follows:

$\mathrm{PCSA}=\frac{m}{\rho * \mathrm{FL}}$

(eqn 1)

where $m$ is muscle belly mass (in $\mathrm{kg}$ ), $\rho$ is muscle density $\left(1.06 * 10^{3} \mathrm{~kg} \mathrm{~m}^{-3}\right.$; Mendez \& Keys, 1960) and $\mathrm{FL}$ is average muscle FL (in $\mathrm{m}$ ). The PCSA calculated in this way is directly related to the force-generating capacity of all muscle fibres (maximal isometric force or $F_{\text {max }}$ ). However, in pennate muscles, only a component of the fibre force (proportional to the cosine of the pennation angle $\theta$ ) is transmitted to the tendon. Correction for this effect results in

$\operatorname{PCSA}=(m /(\rho * \mathrm{FL})) \times \cos \theta$

(eqn 2)

where $\theta$ is the angle of pennation with respect to the line of pull of the muscle. The pennation angle was included in all of our estimates of PCSA, even when angles were small (i.e. close to parallel fibred). To obtain an estimate of $F_{\text {max }}$ PCSA (in $\mathrm{m}^{2}$ ) is multiplied by $0.3 \mathrm{MPa}$ [maximal isometric stress of a vertebrate muscle (Wells, 1965; Medler, 2002); note that gibbon-specific data are not available].

The TCSA was calculated in a similar way as in eqn 1 ; the tendon sample volume $\left(\mathrm{m}^{3}\right)$ was determined by dividing tendon sample mass by tendon density $\left(1.12 * 10^{3} \mathrm{~kg} \mathrm{~m}^{-3} ;\right.$ Ker et al. 1988). This value was then divided by tendon sample length to acquire TCSA. The total TL over MTU length was calculated as a relative value of TL. Although both tendons at origin and insertion were measured, only the data of insertion tendons were included in our analysis, due to the small number of muscles with origin tendons.

Finally, the stress in life (SIL) (in MPa) was calculated by dividing $F_{\max }$ (i.e. PCSA $\times 0.3 \mathrm{MPa}$ ) by TCSA and used as a measurement of the stress in a tendon while the muscle is exerting maximum isometric force, $F_{\max }$ (Ker et al. 2000).

\section{Interspecific comparison}

To allow comparison between specimens of varying size (body mass range, $5.2-12.5 \mathrm{~kg}$ ) and with other primate species, the data 
Table 2 Abbreviations of measured arm muscles

\begin{tabular}{|c|c|}
\hline Muscle & Code \\
\hline Abductor pollicis longus & APL \\
\hline Biceps brachii & B \\
\hline Brachialis & Bra \\
\hline Brachioradialis & $\mathrm{BR}$ \\
\hline Coracobrachialis & $\mathrm{CB}$ \\
\hline Deltoid & $\mathrm{D}$ \\
\hline Dorsoepitrochlearis & DET \\
\hline Extensor carpi radialis brevis & ECRB \\
\hline Extensor carpi radialis longus & ECRL \\
\hline Extensor carpi ulnaris & ECU \\
\hline Extensor digiti minimi & EDM \\
\hline Extensor digitorum brevis & EDB \\
\hline Extensor digitorum communis & EDC \\
\hline Extensor pollicis brevis & EPB \\
\hline Extensor pollicis longus & EPL \\
\hline Flexor carpi radialis & FCR \\
\hline Flexor carpi ulnaris & FCU \\
\hline Flexor digitorum profundus & FDP \\
\hline Flexor digitorum superficialis & FDS \\
\hline Infraspinatus & IS \\
\hline Latissimus dorsi & LD \\
\hline Levator scapulae & LS \\
\hline Palmaris longus & Palm \\
\hline Pars superior seratus anterior & SPSA \\
\hline Pectoralis major & Pmaj \\
\hline Pectoralis minor & Pmin \\
\hline Pronator quadratus & $\mathrm{PQ}$ \\
\hline Pronator teres & PT \\
\hline Rhomboid & $\mathrm{Rh}$ \\
\hline Rhomboid minor & Rmin \\
\hline Serratus anterior & Serr \\
\hline Subscapularis & SSC \\
\hline Supinator & Sup \\
\hline Supraspinatus & SS \\
\hline Teres major & Tmaj \\
\hline Teres minor & Tmin \\
\hline Trapezius & Trap \\
\hline Triceps brachii & $\operatorname{Tr}$ \\
\hline
\end{tabular}

were normalized assuming geometric similarity (cf. Alexander et al. 1981; Thorpe et al. 1999; Payne et al. 2006). Masses were scaled to body mass, lengths to (body mass) $)^{1 / 3}$ and areas to (body mass) ${ }^{2 / 3}$. Muscles were grouped in functional categories, which are given in Table 3. The movements affected by the functional muscle groups of the shoulder are movements of the humerus relative to trunk and are shown in Fig. 1, with flexion/extension taking place in the sagittal plane, abduction/adduction in the frontal plane and endorotation/exorotation in the transversal plane. The functional groups of elbow and wrist muscles follow the classical convention of movements at those joints (flexion/extension and pronation/ supination in the elbow and palmarflexion/dorsiflexion and ulnar/ radial deviation at the wrist) and the scapular muscles are muscles that affect the movement of the scapula. For each functional muscle group the sum of the separate muscle PCSA and mass was taken to result in one value for each muscle group in each individual. The FL was averaged between the containing muscles of that group.
Table 3 Functional categories of dissected muscles

\begin{tabular}{|c|c|c|c|}
\hline Shoulder & Elbow & Wrist & Scapular muscles \\
\hline Flexors & Flexors & Palmar flexors & \\
\hline Pmaj & $B$ * & FDS* & Trap \\
\hline $\mathrm{D}$ & Bra* & FDP* & Serr \\
\hline B & $\mathrm{BR}^{*}$ & $\mathrm{FCU} *$ & SPSA \\
\hline \multirow[t]{5}{*}{$\mathrm{CB}$} & PT & $\mathrm{FCR}^{*}$ & $\mathrm{Rh}$ \\
\hline & FCR & APL & Rmin \\
\hline & Palm & Palm & LS \\
\hline & FDS & EPB & \\
\hline & $\mathrm{FCU}$ & & \\
\hline Extensors & Extensors & Dorsal flexors & \\
\hline $\operatorname{Tr}$ & $\operatorname{Tr} *$ & EDC & \\
\hline Tmaj & & ECRL* & \\
\hline LD & & ECRB* & \\
\hline \multirow[t]{4}{*}{$\mathrm{D}$} & & $\mathrm{ECU} *$ & \\
\hline & & EPL & \\
\hline & & $\mathrm{EDB}$ * & \\
\hline & & EDM & \\
\hline Abductors & Supinators & Ulnar deviation & \\
\hline $\mathrm{D}$ & B & $\mathrm{ECU}$ & \\
\hline \multirow[t]{2}{*}{ SS } & Sup & $\mathrm{FCU}$ & \\
\hline & $\mathrm{BR}$ & EDM & \\
\hline Adductors & Pronators & Radial deviation & \\
\hline Pmaj & $\mathrm{PQ}$ & ECRL & \\
\hline CB & PT & ECRB & \\
\hline Tmaj & BR & APL & \\
\hline \multirow[t]{2}{*}{ LD } & & EPL & \\
\hline & & FCR & \\
\hline \multicolumn{4}{|c|}{ Endorotators } \\
\hline \multicolumn{4}{|l|}{ SSC } \\
\hline \multicolumn{4}{|l|}{ Pmaj } \\
\hline \multicolumn{4}{|l|}{$\mathrm{D}$} \\
\hline \multicolumn{4}{|l|}{ Tmaj } \\
\hline \multicolumn{4}{|l|}{ LD } \\
\hline \multicolumn{4}{|l|}{ Exorotators } \\
\hline \multicolumn{4}{|l|}{ IS } \\
\hline \multicolumn{4}{|l|}{ Tmin } \\
\hline D & & & \\
\hline
\end{tabular}

*Muscles that were used to compare to chimpanzee, human and macaque data as in Thorpe et al. (1999).

Consequently the values (PCSA, mass and FL) were normalized geometrically to the average bodyweight of our gibbons (see above) and finally an average was taken to result in one PCSA, one muscle mass and one $\mathrm{FL}$ value for each functional muscle group in each species.

All measured forelimb muscles were included in the analysis of the gibbon data but, for the comparative analysis (with chimpanzees, macaques and humans), only forelimb muscles that were also measured in Thorpe et al. (1999) were included in the comparison of the different primate species (see Table 3). Primates used for quantitative anatomical comparison were: chimpanzee (Chimp 95 from Thorpe et al. 1999), human (scaled to $50 \mathrm{~kg}$; Thorpe et al. 1999) and macaques (M. mulatta and M. fascicularis; from Cheng \& Scott, 2000), all scaled to the average measured gibbon body mass $(7.7 \mathrm{~kg})$. 
Fig. 1 Definition of different shoulder movements.
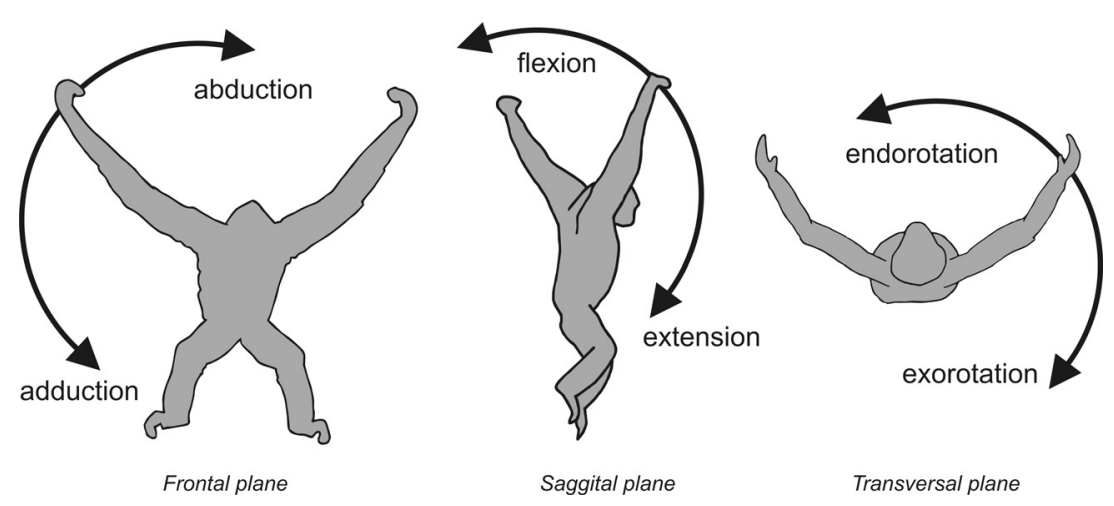

Saggital plane

Transversal plane

\section{Results}

\section{Forelimb muscle anatomy}

In general, the forelimb musculature of gibbons has a similar organization as that of other primates and only a couple of differences were observed between the forelimb musculature of gibbons and that of various other primate species with distinct locomotor repertoires. The origin and insertion of all forelimb muscles, together with observed variations, are presented in Appendix B.

Of the observed differences, the most remarkable is that, in gibbons, the short head of the biceps is monoarticular, whereas it is biarticular in most primates. In gibbons, the short head originates from the lesser tubercle of the humerus, whereas it originates from the coracoid process of the scapula in humans (Gray, 1918) and other primates (Miller, 1952; Kimura \& Takai 1970; Youlatos 2000). As a result, only the long head of the biceps (originating from the supraglenoid) crosses the glenohumeral joint in gibbons.

Also important to note is that we found no anconeus lateralis muscle in any of our gibbon specimens, leaving the triceps as the only elbow extensor in gibbons.

In addition, some clear variations in origin or insertion were found for brachioradialis (BR), APL, flexor digitorum profundus (FDP) and the supinator muscle (Sup) (Appendix B). The BR originates from the lateral supracondylar ridge but its insertion differs among primates. In humans, and occasionally also in siamangs, it inserts on the styloid process of the radius (Gray, 1918), whereas in bonobos, crab-eating monkeys and (most) siamangs its insertion has shifted proximally on the radial shaft and in other gibbons even to the mid-radius. The APL shows some minor variations in both origin and insertion. The origin varies between the proximal part of the radius and ulna in gibbons, to the middle part in crab-eating monkeys, bonobos and humans. Although the insertion is mostly found on the base of metacarpal 1, it can also insert onto the trapezium (some siamangs and bonobos) or even to the sesamoid bones of the pollex (crab-eating monkeys). For the FDP, we noted substantial interindividual variation (within our gibbon sample) in fusion of the digital tendons and/or muscle bellies, with most variation occurring within the siamangs.

Like monkeys and most apes (Howell \& Straus, 1961), gibbons possess a dorso-epitrochlearis muscle that connects the latissimus dorsi to the short head of the biceps. However, in some gibbon specimens this muscle has not only a fleshy insertion on the short head of the biceps but also inserts via a narrow tendon on the medial epicondyle of the humerus, a feature also seen in other non-human primates (bonobos: Miller, 1952; atelines: Youlatos, 2000). In humans, this muscle is reduced to fascia (Kimura \& Takai, 1970; Aiello \& Dean, 1990).

Within our gibbon sample some individual variation in muscle courses was observed (see above) but we did not find any consistent differences in origin and insertion of forelimb muscles between the genus Symphalangus (siamangs) and Hylobates or between the different gibbon species (Appendix $B$ ). [Note that when we mention gibbons in general, we refer to all four measured species, including siamangs.] Overall, muscles in the forearm display a remarkably high degree of fusion of muscle bellies (e.g. FDS, FDP and APL + EPL) as well as tendons (e.g. EDC and $E D M+E C U)$. In addition, shoulder, elbow and wrist muscles are linked, forming a proximo-distal muscle chain comprising LD, DET, B and FCR/Palm (Jungers \& Stern, 1980).

\section{Forelimb muscle dimensions}

Below, we present the muscle mass, PCSA, FL and tendon characteristics of the forelimb muscles of the four gibbon species studied. Unless stated otherwise, values given are always interspecies mean (i.e. mean of the four species means + SD) and scaled to the average measured body mass of $7.7 \mathrm{~kg}$. The mean values of each muscle for each species can be found in Appendix A.

\section{Muscle mass}

The unilateral forelimb muscle mass accounts on average for $8.2 \pm 0.8 \%$ (mean $\pm S D$ ) of the average body mass of gibbons, corresponding to ca. $641 \mathrm{~g}$ of muscles per forelimb. The greatest part $(57 \pm 0.5 \%)$ of the forelimb muscle mass consists of muscles that cross the shoulder (glenohumeral 


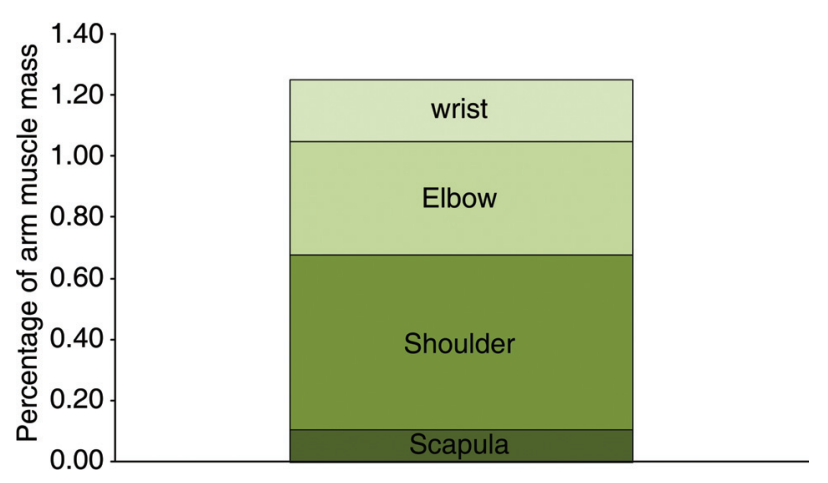

Fig. 2 Relative muscle mass distribution in an average gibbon forelimb. (Note that because of biarticular muscles, the total adds up to more than $100 \%$.)

joint) (Fig. 2). Within these shoulder muscles, $50 \pm 1.5 \%$ of the muscle mass contributes to extension and $48 \pm 1.4 \%$ to flexion, indicating that a large part of the muscles in the shoulder are those for lowering and lifting the arm in the sagittal plane (extensors and flexors, respectively). However, most of these muscles also contribute to endorotation $(42 \pm 0.6 \%)$, exorotation $(36 \pm 2.1 \%)$ and adduction $(40 \pm$ $1.8 \%$ ). Only abductor muscles (for lifting the arm in the frontal plane) form a smaller share of the shoulder musculature $(18 \pm 0.7 \%)$. In the elbow and wrist, the flexors are the dominant group $(78 \pm 2.2 \%$ and $81 \pm 2.6 \%$ of the elbow and wrist muscle masses, respectively) and together they make up more than one-third $(35 \pm 1.3 \%)$ of the total forelimb musculature. A similar forelimb muscle mass distribution is found for each of the four gibbon species.

\section{Physiological cross-sectional area}

The deltoid (D) has on average the largest PCSA (10.67 \pm $2.28 \mathrm{~cm}^{2}$ ) and hence the highest force-producing capacity of all forelimb muscles $\left(F_{\max }=326 \mathrm{~N}\right)$, followed by the triceps $\left(8.48 \pm 1.17 \mathrm{~cm}^{2}\right)$ and the flexor digitorum profundus and superficialis muscles (FDP, $8.19 \pm 1.85 \mathrm{~cm}^{2}$; FDS, $7.41 \pm$ $1.48 \mathrm{~cm}^{2}$ ). The pectoralis major, latissimus dorsi and biceps are exceptionally large in pileated gibbons compared with other gibbons, whereas lar gibbons have larger trapezius, deltoid and supinator muscles (see Appendix A for values). It is also remarkable that both lar and pileated gibbons have relatively larger deeper digital flexors (lar: FDP, $10.15 \mathrm{~cm}^{2}$, FDS, $6.68 \mathrm{~cm}^{2}$; pileated: FDP, $9.19 \mathrm{~cm}^{2}$, FDS, $5.71 \mathrm{~cm}^{2}$ ), whereas moloch gibbons and siamangs have relatively larger superficial digital flexors (moloch: FDP, $5.98 \mathrm{~cm}^{2}, F D S, 8.93 \mathrm{~cm}^{2}$; siamang: FDP, $7.45 \mathrm{~cm}^{2}$, FDS, $8.33 \mathrm{~cm}^{2}$ ). Of the total PCSA of all forelimb muscles, $51 \%\left(53.94 \mathrm{~cm}^{2}\right)$ is situated in the shoulder musculature, $38 \%\left(40.09 \mathrm{~cm}^{2}\right)$ is situated in the elbow, $27 \%\left(28.48 \mathrm{~cm}^{2}\right)$ in the wrist musculature and $9 \%$ $\left(6.04 \mathrm{~cm}^{2}\right)$ is formed by the scapular muscles. Although there is some variation among gibbon species, the general pattern is the same (Fig. 3a). The PCSA of the functional muscle groups shows that the elbow and wrist muscula- ture have a clear dominance for flexion (flexors constitute $71 \%$ of the elbow musculature and $81 \%$ of the wrist musculature) (Fig. 3a). In the shoulder, the extensors are the group with the largest PCSA $(27.31 \mathrm{~cm}$ or $50 \%$ of the shoulder musculature), closely followed by the endorotators $\left(24.56 \mathrm{~cm}^{2}\right.$ or $\left.43 \pm 4 \%\right)$, flexors $\left(23.2 \mathrm{~cm}^{2}\right.$ or $\left.40 \pm 3 \%\right)$ and exorotators $\left(19.54 \mathrm{~cm}^{2}\right.$ or $\left.36 \pm 4 \%\right)$. Both abductors and adductors form a smaller part of the total shoulder PCSA $\left(13.73 \mathrm{~cm}^{2}\right.$ or $25 \pm 2 \%$ and $13.08 \mathrm{~cm}^{2}$ or $24 \pm 4 \%$, respectively).

\section{Fascicle length}

On average, the latissimus dorsi (LD) has the longest muscle fascicles (mean FL, $138.46 \pm 11.24 \mathrm{~mm}$ ). [See Appendix A for values of separate muscles for each species.] The elbow supinators (FL, $66.50 \mathrm{~mm}$ ), scapular muscles (FL, $63.53 \mathrm{~mm}$ ) and shoulder adductors ( $\mathrm{FL}, 80.10 \mathrm{~mm}$ ) all have long muscle fascicles (Fig. 3b). In the wrist, the FL is low compared with more proximally located forelimb muscles. Although some minor differences were observed, the overall pattern of the $\mathrm{FL}$ of the functional muscle groups is similar across the four gibbon species.

\section{Tendon length and stress in life}

Tendons are prominent in most muscles of the gibbon forelimb but are particularly extensive in muscles crossing the wrist joint. Figure $3 c$ shows the relative (insertion) TL (TL : MTU) for each functional muscle group. Only muscles for which tendon data are available are included; data of FDS, FDP, EDC, EDB, EDM and EPL tendons are omitted as these tendons were incomplete in most of our specimens (see Materials and methods). The longest tendons (relative to muscle belly length) are found in the muscles that cross the wrist muscles, in particular in the flexor and ulnar and radial deviator groups (Fig. 3c). The shoulder muscles, especially the adductors, have the shortest tendons.

The SIL, an estimate of the stress in a tendon while the muscle is exerting maximum isometric stress (Ker et al. 2000), is largest for the tendons of the elbow and wrist/ digital flexors (B and FDS) (Fig. 4). Lar gibbons also have a particularly high SIL for tendons of the EPL, EPB and APL, whereas pileated gibbons have high SILs in the tendons of FCR and EDB. For most tendons, siamangs have relatively lower SIL values; however, it should be noted that this parameter presents substantial inter- and intraspecific variation.

\section{Discussion}

\section{Are there anatomical adaptations to a brachiating lifestyle?}

In this study, gibbons, as specialized brachiators, were compared with 'modified' brachiators (bonobo and chimpanzee), New World semi-brachiators (atelines) and non-brachiators 

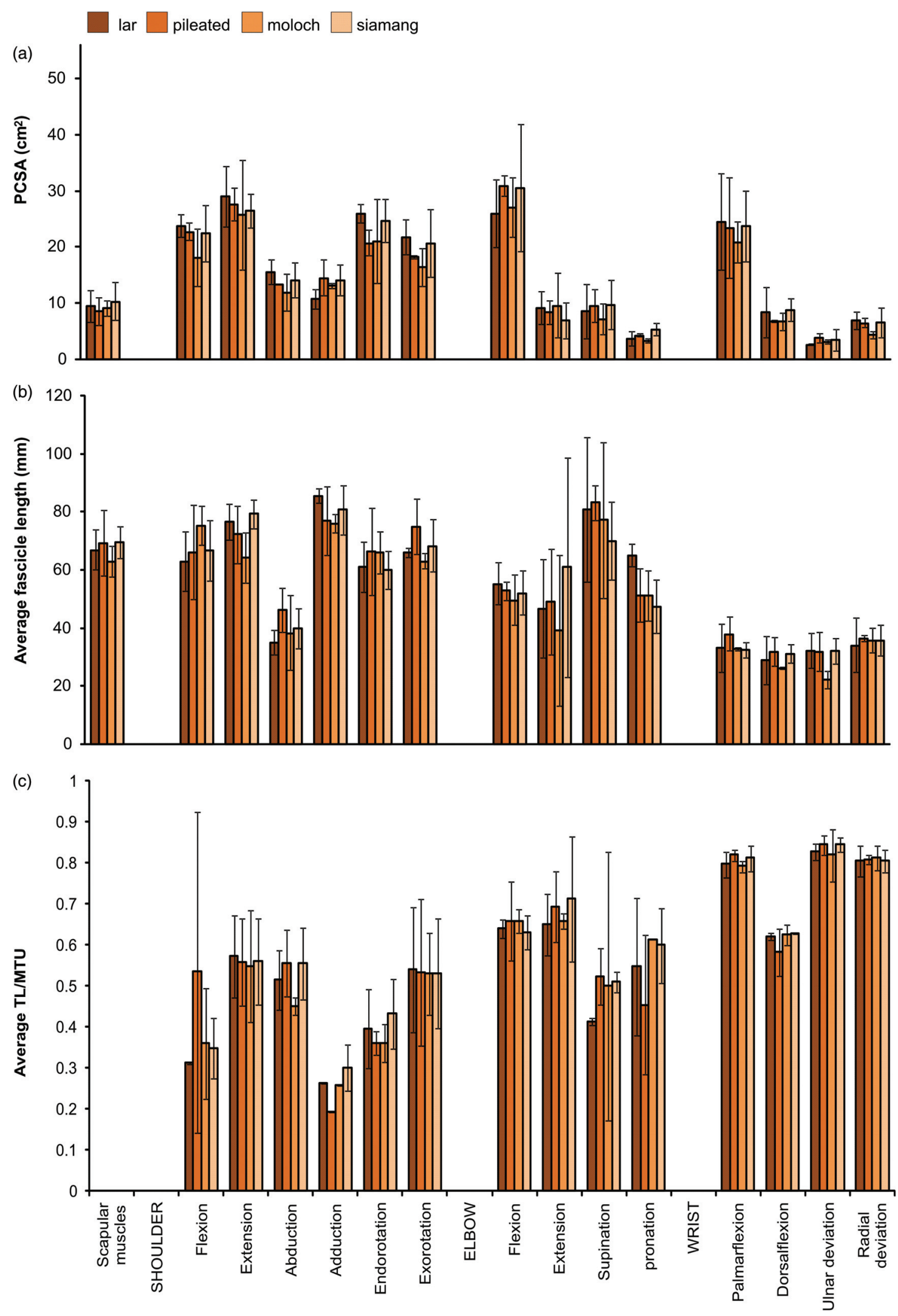

Fig. 3 (a) Total physiological cross-sectional area (PCSA), (b) average fascicle length and (c) average tendon length [relative to muscle-tendon unit (MTU)] of each functional muscle group of the forelimb averaged for each of the four measured gibbon species and normalized to the average measured gibbon weight. Error bars show mean + SD. [In (c) only those muscles are used that have insertion tendons.] 


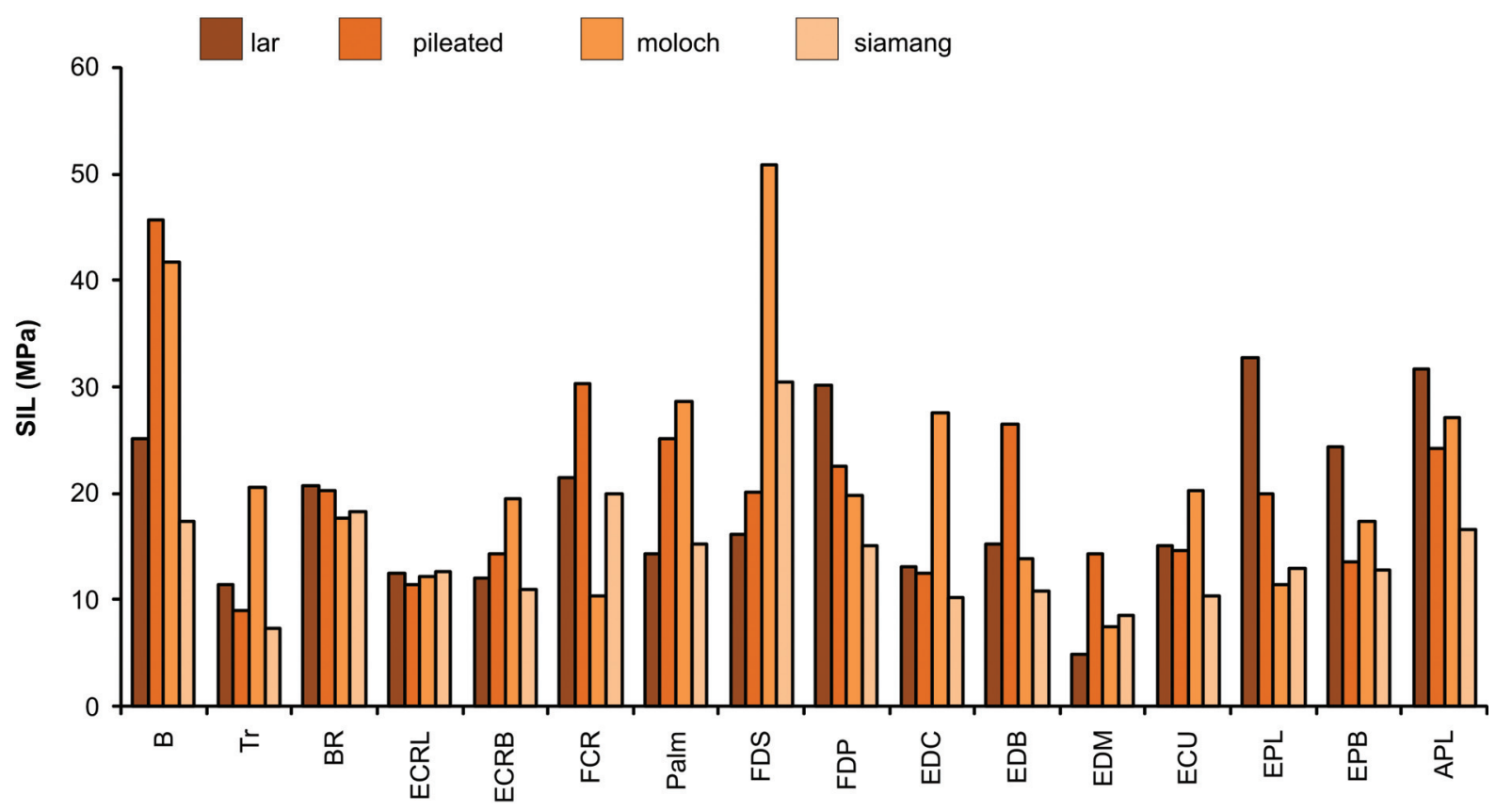

Fig. 4 Average stress in life (SIL) for those muscles that have insertion tendons and for which the tendon cross-sectional area (TCSA) could be determined for each of the four measured gibbon species and normalized to the average measured gibbon weight.

(crab-eating monkeys, humans and macaques). Although the locomotor anatomy of gibbons is qualitatively similar to the anatomy of great apes (Swindler \& Wood, 1973), the highly suspensory mode of locomotion of gibbons has contributed to some specialized anatomical features (e.g. well-developed scapular spine, long forearms relative to both humerus and body size, and radii that are thicker sagittally than transversely) (Takahashi, 1990). Other features are, to some extent, also found in atelines (e.g. axially elongated scapulae and curvature of the clavicle) (Takahashi, 1990; Voisin, 2006) because they also frequently arm-swing, although in a different way to gibbons (assisted by the prehensile tail).

A remarkable difference between gibbons and other primates is the site of origin of the short head of the biceps brachii. Whereas it originates on the coracoid process of the scapula in most primates, the short head of the biceps originates from the lesser tubercle of the humerus in gibbons. Therefore, whereas in most primates both the long head and the short head of the biceps run over the shoulder, giving the entire muscle a biarticular function (crossing shoulder and elbow joint), in gibbons only the long head crosses the shoulder and thus works biarticularly, whereas the short head works only at the elbow. Because of this, the biceps brachii in gibbons might have a reduced flexion capacity in the shoulder, as only the long head can work at shoulder level, although this apparently reduced capacity could be compensated by an increase in PCSA of the biceps in gibbons compared with other primates. Moreover, despite the fact that Miller (1932) proclaims that there can be doubling of one of the heads of the biceps in gibbons and 'modified' brachiators, we observed two biceps heads in all of our gibbon specimens and in one siamang specimen (Siamang 1) the biceps was not two-headed but rather fused to a single muscle head. Fusion of arm muscles was frequently observed in our gibbon specimens. Fusion mainly occurred within and between the muscle bellies of FDS and FDP and between the muscle bellies of APL and EPL. The different tendons of EDC showed fusion as well as the tendons of EDM with the tendons of ECU. We also observed two muscle chains running from the shoulder to the digital muscles, as described by Jungers \& Stern (1980). The dorsal muscle chain is formed by fusion of the latissimus dorsi, dorso-epitrochlearis, biceps short head (Bsh) and flexor digitorum superficialis (FDS), whereas the ventral chain consists of the pectoralis major, Bsh and FDS. These chains have long been thought to have a force-transmitting function from shoulder to fingertips (Andrews \& Groves, 1976) but have been shown by Jungers \& Stern (1980) to be only a morphological consequence of the rearrangement of the origin of the short head of the biceps. Although the flexion function of the biceps at the shoulder is probably reduced by the shift in origin of the Bsh, the leverage for elbow flexion is improved due to an increased insertion area (coracoid process vs. lesser tubercle and midshaft humerus; Jungers \& Stern, 1980). This is advantageous for brachiation, where the arms are used to hoist the body by extending the arm at the shoulder and flexing it at the elbow. Although those chains do not seem to have an obvious force conductive function from proximal to distal, or show phasic simultaneity during brachiation (electromyographic study of Jungers \& Stern, 1980), it is possible 
that the fusion of muscle bellies and tendons in the forearm contributes to an increased concerted action of different muscles (fusion can be seen as two muscles working together as one more powerful muscle). However, it might lead to less accurate finger movements, and hence manipulation skills, due to the loss of separate muscle activation. These less accurate movements (personal observation, but see Prime \& Ford, 2006) may also be a consequence of the fact that gibbons do not have separate digital extensors like macaques (all digits separately) and bonobos (to digits 1, 2 and 5) (Miller, 1952; Kimura \& Takai, 1970) but gibbons do have an EDM to the fifth phalanx, an APL to the thumb and an EDB that can have tendons to digits 24 (Appendix B). Therefore, they will have no problem in moving their little finger or thumb separately but the three middle fingers will move mostly simultaneously. Another muscle that is missing in gibbons is the anconeus lateralis muscle [absent in all of our specimens but Gibbs et al. (2002) mention the presence of this muscle in gibbons], a prominent elbow extensor (part of the triceps complex) that is present in humans and bonobos and also in macaques (Gray, 1918; Miller, 1952; Kimura \& Takai, 1970). Therefore, although gibbons have multiple elbow flexors (biceps, brachialis and brachioradialis), only the triceps works as an extensor of the elbow and even though the triceps has one of the largest PCSAs, it is not able to match the PCSA of its antagonists, the elbow flexors.

\section{Gibbon muscle dimensions: the key to efficient brachiation?}

Our results clearly indicate that there is a proximal to distal distribution of muscle mass in the gibbon forelimb (Fig. 2), with the heaviest muscle groups near the body and long tendons running to the fingers. Although all primates (and even most mammals) show this kind of muscle distribution, the pattern is exaggerated in gibbons as they are the only ones that have a long forearm relative to both humerus and body size (Takahashi, 1990), resulting in forearm muscles with high relative TLs (high TL : MTU ratios) (Fig. 3c). This distribution is advantageous for brachiating in two ways: on the one hand, because of the low distal muscle mass and the long (fore)arm, the non-supporting arm can swing fairly quickly and with little power input back up to the next handgrip because the segment centre of mass (COM) lies near the body (cf. cursorial mammals). On the other hand, the pendulum effect of the body during contact with the overhead support can be enhanced because muscle mass is centred near the body (and away from the pivot point, i.e. the hand). Gibbons are also capable of moving their COM closer to, or further from, the handgrip to enhance the pendulum effect (affecting swing speed and velocity of the body). They flex or extend their elbows and lift their legs to shift the COM. The further away that the COM is from the pivot point, the slower the swing movement will be but the gibbons will then be able to reach further and consequently the velocity of the body moving forward will be higher. In this way, the COM follows the pattern of a pendulum and mechanical energy recovery is possible (Bertram et al. 1999; Bertram \& Chang, 2001; Usherwood et al. 2003). The muscles that seem most suitable for this action are, based on muscle masses and PCSAs, the shoulder muscles, elbow flexors and wrist/ digital flexors. The deltoid, in particular, provides a significant advantage during brachiation, having the largest PCSA and contributing to different movements of the humerus (abduction and flexion/extension).

From the muscle mass results, we can conclude that shoulder muscle masses are almost equally distributed over the functional groups. Only abductor muscles (i.e. D and SS) have a much lower mass, hence shoulder abductors are the shoulder muscles with the lowest capacity for power production and this seems to be the case in all gibbon species studied. For brachiation, arm abductors do not seem very important (at least not for powerful arm motion) as arm motion predominantly occurs in the sagittal plane and in a suspensory position the arm is fully abducted under the influence of gravity. However, the abductors might be important in reaching for overhead supports that are not necessarily placed in the sagittal plane of the body and therefore have to be able to act quickly and accurately but can be less powerful. In the elbow and wrist, we find a clear dominance of flexor muscle groups. Even though the triceps muscle has one of the highest individual PCSAs, it is small compared with the large elbow flexor group. It is the only elbow extensor in gibbons ( $\mathrm{m}$. anconeus lateralis is not present in gibbons) and its function as an elbow extensor is consequently not negligible. However, during brachiation (overhead support) the elbow can be extended passively under the influence of gravitation and active/powerful elbow extension is probably only necessary for movements such as climbing or reaching for food. During brachiation, the triceps muscle will probably primarily act at the shoulder.

In suspension, e.g. during brachiation, the arms undergo tension forces instead of compressive forces as occurring in quadrupedal locomotion. Although there is also some compression in the joints due to muscle contraction, the muscles have to be able to work primarily against these gravitational forces to move the body up and forward. Therefore, flexor muscles in the elbow and wrist (working against gravity) will have to be developed more than extensor muscles (working with gravity). In the shoulder, however, we expect extensor muscles (pull arm back and body up in the sagittal plane) and adductor muscles to be more developed. Figure $3 a$ shows that wrist and digital flexors, elbow flexors and shoulder extensors, rotators and flexors are capable of producing large forces. Rotator muscles in the shoulder might be important to stabilize the body during brachiation and prevent it from swinging 


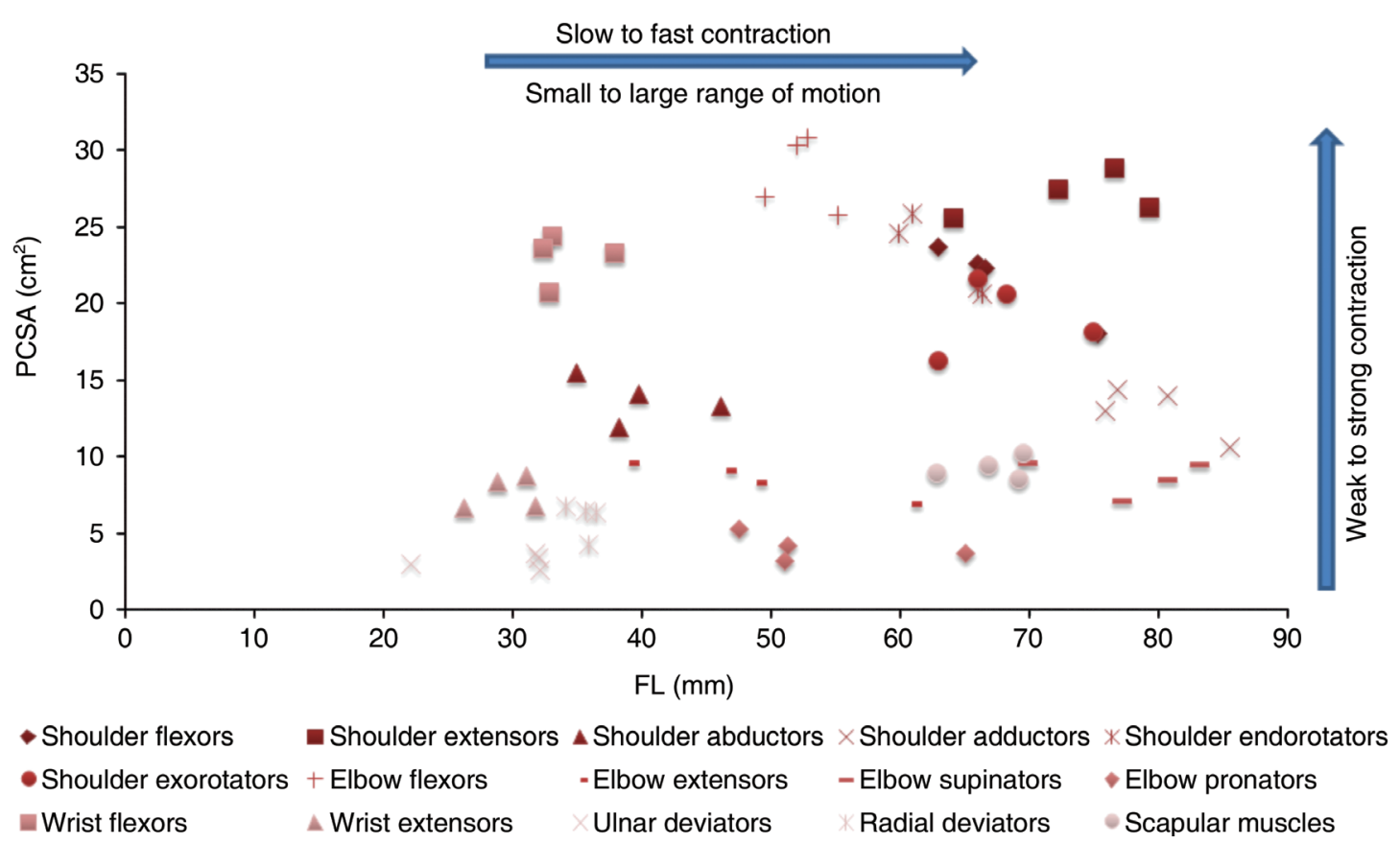

Fig. 5 Fascicle length (FL) against physiological cross-sectional area (PCSA) for each functional muscle group of the four measured gibbon species. This indicates the actions to which the muscle groups are best suited.

mediolaterally rather than forward. These muscles might also be necessary in reaching (e.g. to reach for branches or food).

Of course PCSA and mass are not the only parameters that can predict the capabilities of a muscle. Although FL is included in the calculation of PCSA, it is an important factor on its own that can give information about the range of motion in which a muscle can produce force and the velocity at which it can contract. The latter is also affected by the fibre type distribution of the muscle and eventually the muscle moment arm also influences the speed of movement. Gibbon wrist and digital flexors have relatively low FLs (Fig. 3b), meaning that they might not be able to work over a large range of motion or contract very fast, although they are fairly strong.

Figure 5 shows the FL (average for the functional muscle group) and PCSA (sum of the muscle PCSA in each functional group) of the functional muscle groups. Note that the characteristics given below are relative parameters that hold within our gibbon sample only. The most powerful muscles (large PCSA and long FL) are found in the top right corner and include shoulder flexors, extensors, rotators and elbow flexors. In the bottom right corner, we find muscles with a large range of motion and capacity for fast contraction but with little force (long FL and small PCSA). These muscles are shoulder adductors, elbow extensors, pronators and supinators and muscles of the scapula. These muscles are not necessary to provide high forces (e.g. elbow extensors work with gravity) but will be able to work over a wide range of joint angles and at high contraction speed. The relatively low PCSA of the shoulder adductors might be due to the fact that brachiation mainly occurs in the sagittal plane. In addition, in a suspensory position (i.e. the arm raised above the body), it is possible to achieve adduction of the arm by combined extension and endorotation. The adductors are probably more important in other movements, such as climbing or reaching for food or branches, or for stabilizing the shoulder. The wrist (and digital) flexors are found in the top left corner, meaning that they can produce a lot of force but have a small range of motion (low power). The other muscles that work at the wrist, as well as the shoulder abductors and elbow extensors, have a low FL and PCSA, and are probably less important for brachiation. They might have a stabilizing function and/or contribute to other less powerful and more precise movements, such as reaching for food, manipulation and grooming.

\section{Tendon function: efficient force production vs. a product of optimal mass distribution}

The gibbon's elbow and wrist flexors are characterized by a relatively high SIL (Fig. 4). A high SIL was found for Bra and $B$ and for most wrist flexors (i.e. FDS, FDP, FCR, Palm and $A P L)$, surpassing the average SIL of mammalian tendons (13 MPa; Ker et al. 1988). The high SIL of the tendons of these muscles is due to the combination of a high PCSA, and hence strength, and a relatively low TCSA, which will result in substantial tendon stretch, thus creating the possibility for storage of elastic strain energy. The B and Bra muscles, however, do not have long tendons and it seems unlikely that their high SIL represents a capacity for energy storage 

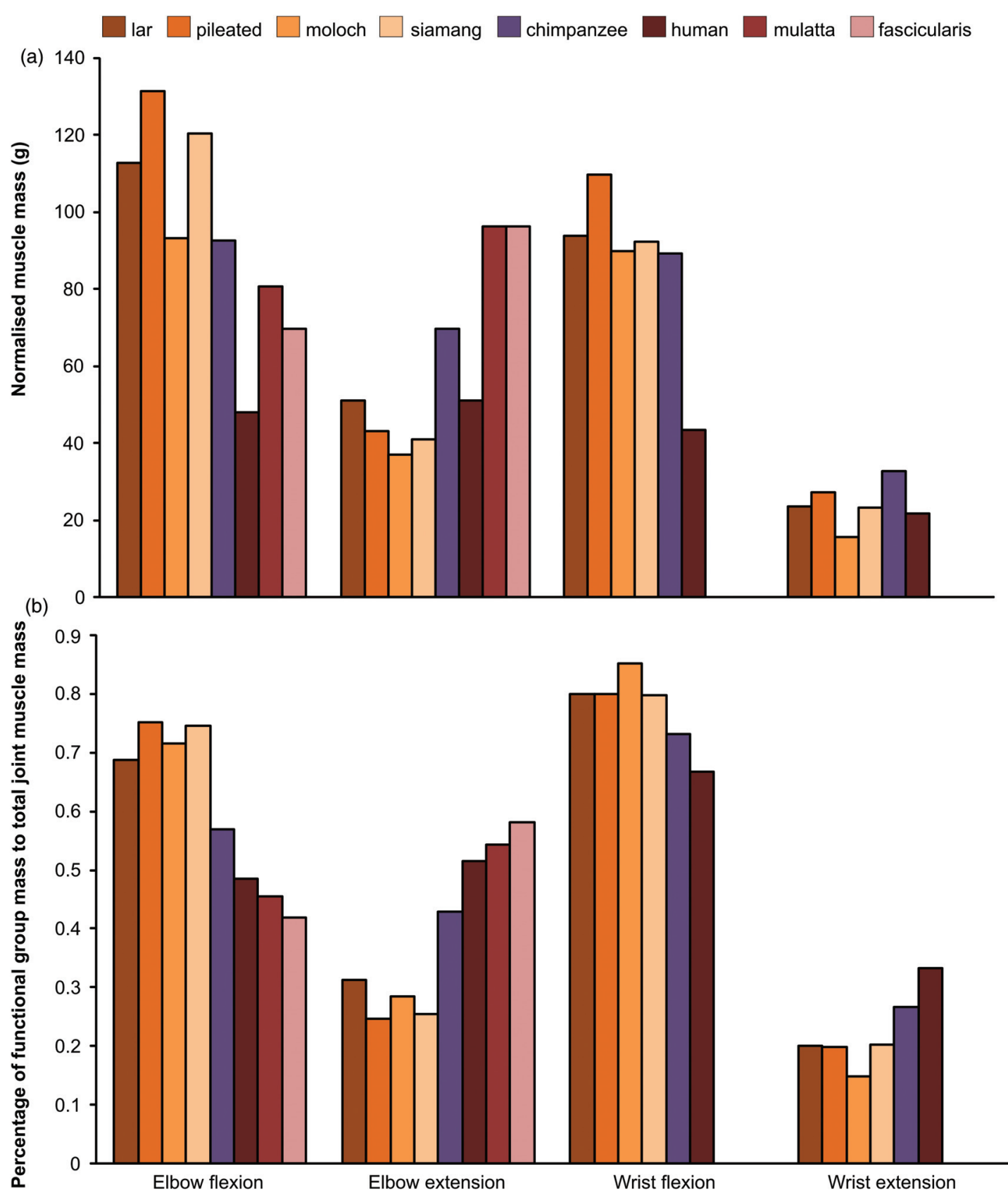

Fig. 6 Muscle mass comparison with non-specialized brachiators. Functional muscle groups contain only those muscles used by Thorpe et al. (1999). Chimpanzee and human data from Thorpe et al. (1999) and macaque data from Cheng \& Scott (2000). All data are normalized to the measured average gibbon weight $(7.7 \mathrm{~kg}$ ). (a) Summed-up values and (b) proportional values (relative to total elbow or total wrist muscle mass, respectively).

in the tendon. The wrist flexors, however, have relatively long tendons, which are generally more compliant, meaning that the muscle will be able to contract nearly isometrically, leading to a more economical force production (Biewener, 1998; Alexander, 2002; Roberts, 2002). Although the long tendons might be merely a by-product of optimal mass distribution in the forelimb (muscle bellies as proximal to the body as possible), the high forces generated by the muscles (high PCSA) might also be able to stretch the long, compliant tendons, allowing energy-saving via storage and recoil of elastic energy. However, it should be noted that there is a lot of interindividual and interspecific variation in the SIL values. As the muscle PCSA does not show much variation, this must be because of the TCSA. Although care was taken when assessing the tendon mass and length (to calculate TCSA), it is possible that this variation occurs due to a measuring error rather than representing actual biological variation. 


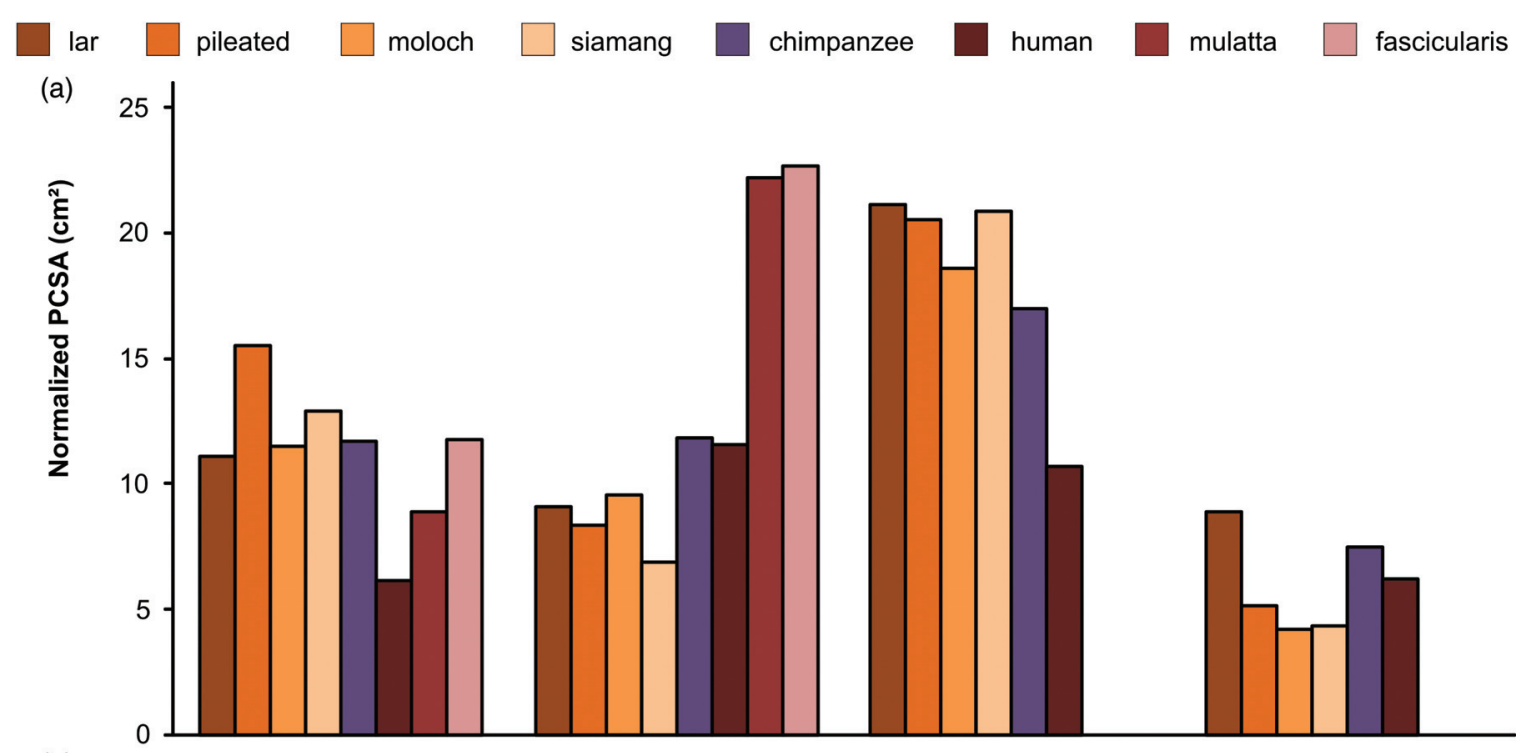

(1)

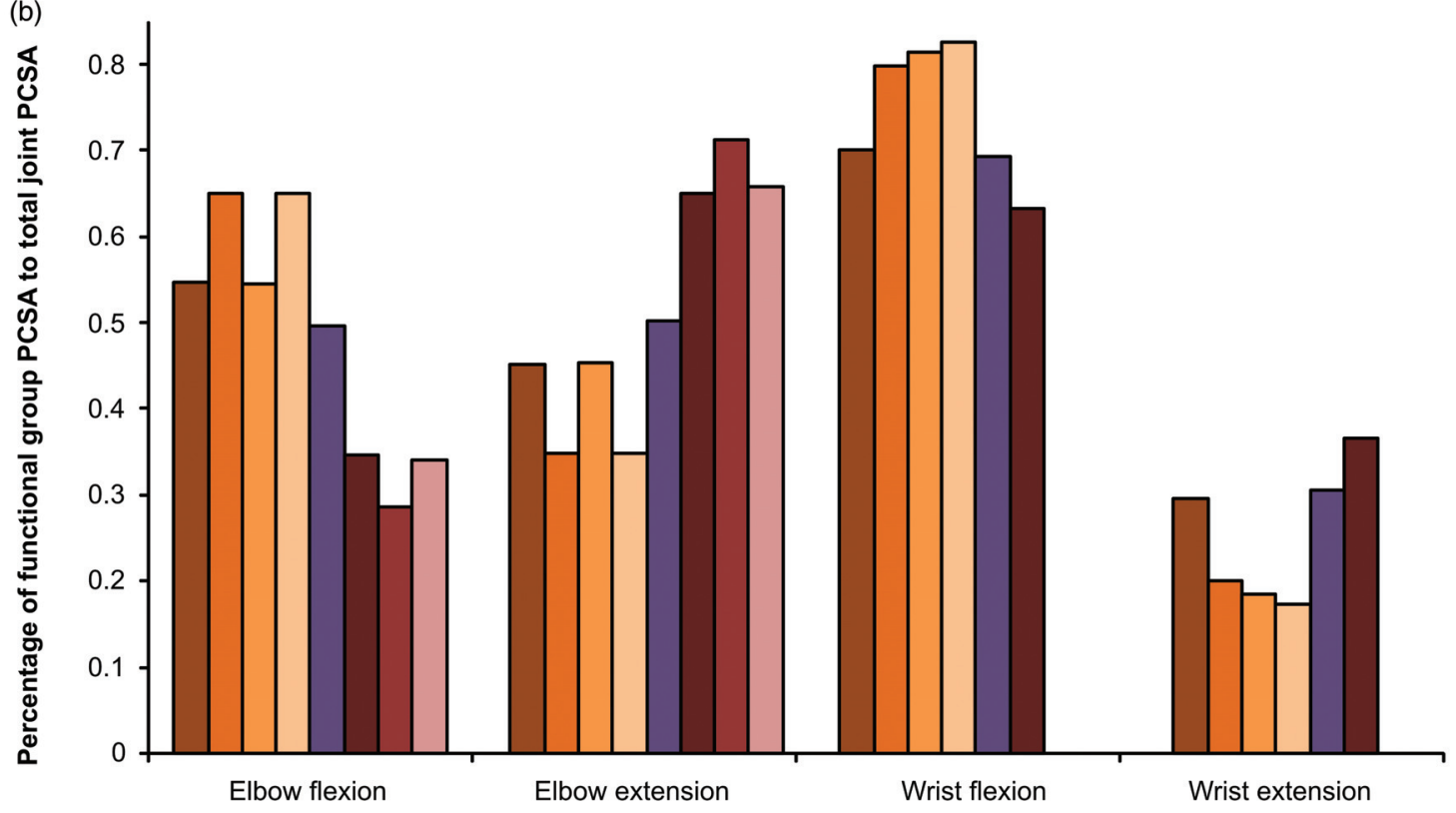

Fig. 7 Muscle physiological cross-sectional area (PCSA) comparison with non-specialized brachiators. Functional muscle groups contain only those muscles used by Thorpe et al. (1999). Chimpanzee and human data from Thorpe et al. (1999) and macaque data from Cheng \& Scott (2000). All data are normalized to the measured average gibbon weight $(7.7 \mathrm{~kg}$ ). (a) Summed-up values and (b) proportional values (relative to total elbow or total wrist PCSA, respectively).

\section{What muscle capacities are unique to gibbons?}

For the wrist and digital muscle masses and PCSAs (Figs 6a, 7a), we do not see much difference between the nonhuman primate species. However, if we look at the ratio of wrist flexors to wrist extensors (Fig. 6b for mass; Fig. 7b for P(SA), there seems to be a decreasing share of flexors and an increasing share of extensors from specialized (wrist flexor mass and PCSA both $\pm 80 \%$ ) over 'modified' brachiators (wrist flexor mass 73\% and PSCA 69\%) to non-brachiators (wrist flexor mass 67\% and PCSA 63\%). For the elbow muscles this is even more obvious, with the quadrupeds and bipeds (macaques and humans) clearly having a greater share of extensors (elbow extensor mass $52-58 \%$ and PCSA 65$76 \%$ ) in comparison to gibbons, whose elbow flexors are relatively larger and stronger (elbow flexor mass $69-75 \%$ and PCSA 55-65\%). Chimpanzees, as 'modified' brachiators, lie somewhere in between (elbow flexor mass $57 \%$ and PCSA 50\%). For the FLs (Fig. 8) of the elbow flexors we find similar results (decreasing FL of elbow flexors from specialized over 'modified' to non-brachiators), suggesting that gibbons do not only have stronger elbow flexors but that these muscles will also have a wider range of motion and possibly a higher contraction speed (more power; 


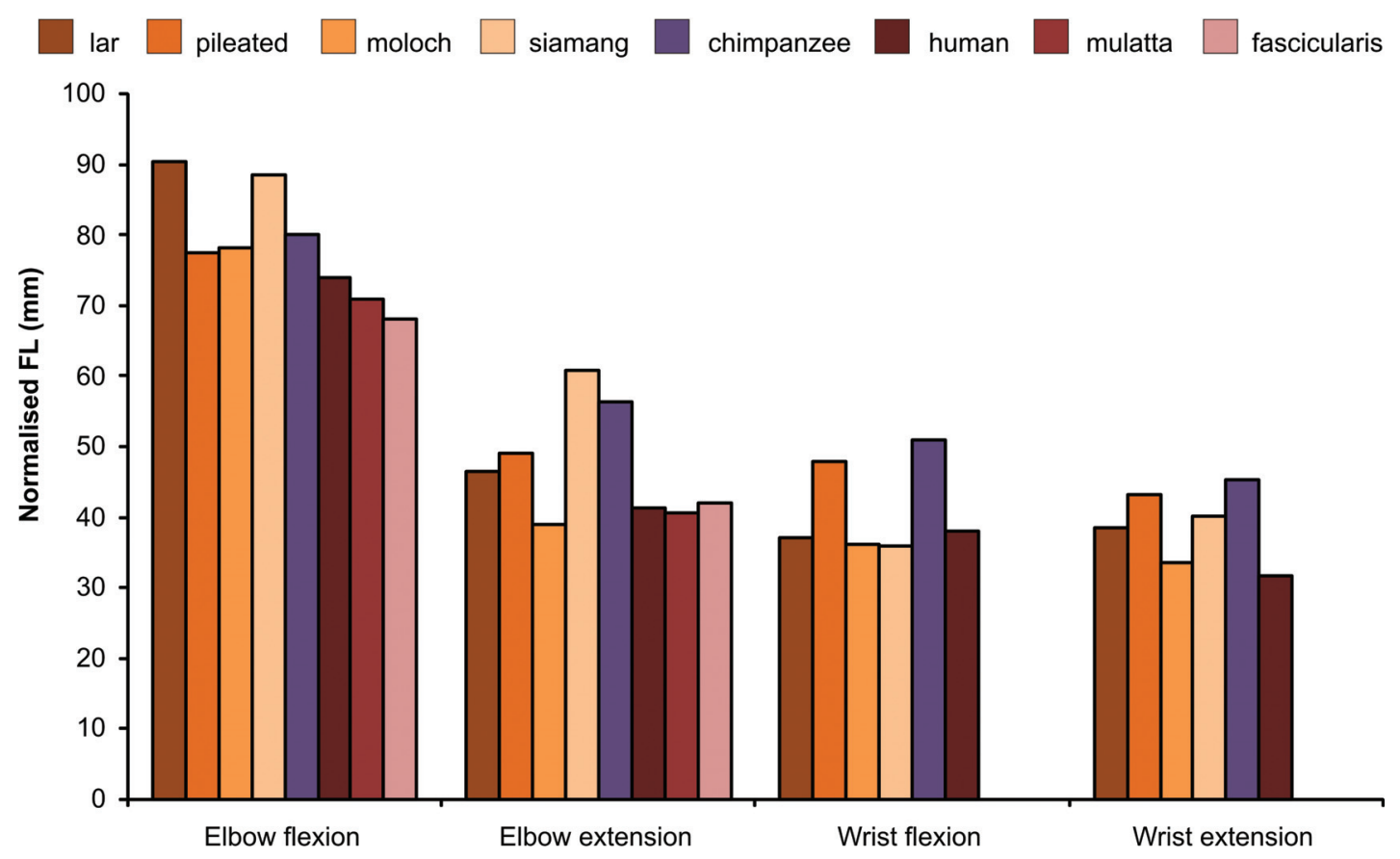

Fig. 8 Average fascicle length (FL) comparison with non-specialized brachiators. Functional muscle groups contain only those muscles used by Thorpe et al. (1999). Chimpanzee and human data from Thorpe et al. (1999) and macaque data from Cheng \& Scott (2000). All data are normalized to the measured average gibbon weight $(7.7 \mathrm{~kg})$.

although this will also depend on the fibre type of the muscle) (Fig. 8). Moreover, for all studied primate species, the elbow flexors seem to have a higher FL compared with the elbow extensors, concluding that, in general, elbow flexors are more suitable for a wide range of motion and have a faster contraction capacity than elbow extensors. In the wrist and digital muscles, no clear differences in $\mathrm{FL}$ between species or between antagonistic muscle groups are found. This suggests once again that these muscles are not tightly linked to the specific locomotor mode of gibbons, i.e. brachiation. It is most likely that this similarity in FLs of the muscles of the wrist of different primates reflects adaptation to locomotion in the same, arboreal habitat, where grasping is important (low FL and high PCSA of wrist/digital flexors). Note that the values for macaques are optimal FLs, which are measured FLs normalized to the optimal sarcomere length of macaques. Unfortunately, data of wrist and digital muscles of strictly quadrupedal, terrestrial primates were unavailable, limiting an extensive interspecific comparison. Cheng \& Scott (2000) did provide some masses and PCSAs of the shoulder muscles, allowing us to compare LD and Tmaj across primates with different locomotor specializations. The statement of Fleagle (1979) that both latissimus dorsi and teres major should be particularly large in brachiating species is not supported by our results. The normalized values of LD and Tmaj muscle mass and PCSA give similar results for specialized, modified and non-brachiating primates, indicating that these muscles are not specifically linked to brachia- tion but rather adapted for a large range of movements (e.g. climbing, grasping and reaching) occurring in these different primates. It should also be noted that for a thorough anatomical comparison of several primate species, it is important to take phylogenetic effects into account (closely related species can have similar anatomy regardless of their differences in locomotion habits or habitat). However, as our primary goal was to provide a quantitative analysis of the functional anatomy of the gibbon forelimb, rather than a detailed interspecific comparison of primate forelimb anatomy, we only present a rough comparative analysis mainly as a framework for our data. We can conclude from our analysis that the high proportion of elbow flexor muscles in gibbons is linked to their unique locomotor mode, i.e. brachiation.

\section{Conclusion}

This study presents detailed anatomical data of the forelimb musculature of four gibbon species $(H$. lar, H. moloch, $H$. pileatus and S. syndactylus). No substantial differences in forelimb anatomy were found between the different gibbon species and muscle dimensions are comparable when normalized to the same body mass. This is an important finding as it allows us to generalize the anatomy of 'the gibbon' and provides the opportunity to extrapolate published work on brachiating lar gibbons to other species.

Overall, gibbons have shoulder flexors, extensors, rotator muscles and elbow flexors with a high power or 
work-generating capacity. In addition, elbow flexor tendons have a high SIL, pointing to a possible energy storage capacity. Wrist flexors have a high force-generating capacity but seem restricted to a small range of motion (low $\mathrm{FL}$ ). The wrist flexor tendons have a high SIL and a high FL : MTU ratio, giving them the capacity to store and release strain energy in their tendons, although this might also be merely a by-product of an optimal mass distribution and long forearm length. The shoulder flexors, extensors, rotator muscles, elbow flexors and wrist flexors are expected to contribute the most in brachiation and especially the elbow flexors of gibbons are more powerful, compared with those of non-specialized brachiators. Although brachiation on a horizontal and fixed substrate might require little energy input, these muscles will be necessary to actively regulate the movement of the body COM and maintain the most energetically effective path when brachiating on compliant, varying and unpredictable substrates.

\section{Acknowledgements}

This study was supported by a research grant to F.M. from the University of Antwerp and the Fund for Scientific Research, Flanders (Belgium). Structural support was provided by the Centre for Research and Conservation of the Royal Zoological Society of Antwerp. We also thank the Royal Zoological Society of Antwerp and NMS for provision of gibbon cadavers and the Royal Society International Joint Project for travel funding.

\section{References}

Aiello LC, Dean MC (1990) An Introduction to Human Evolutionary Anatomy. London: Academic Press.

Alexander RM (2002) Tendon elasticity and muscle function (Review). Comp Biochem Phys A 133, 1001-1011.

Alexander RM, Jayes AS, Maloiy GMO, Whatuta EM (1981) Allometry of the leg muscles of mammals. J Zool 194, 539-552.

Anapol F, Gray JP (2003) Fiber architecture of the intrinsic muscles of the shoulder and arm in semiterrestrial and arboreal guenons. Am J Phys Anthropol 122, 51-65.

Andrews P, Groves CP (1976) Gibbons and brachiation. In Gibbon and Siamang: A Series of Volumes on the Lesser Apes, Vol. 4: Suspensory Behavior, Locomotion and other Behaviors of Captive Gibbons: Cognition (ed. Rumbaugh DM), pp. 167-218. Basel: Karger.

Bertram JEA, Chang YH (2001) Mechanical energy oscillations of two brachiation gaits: measurement and simulation. Am J Phys Anthropol 115, 319-326.

Bertram JEA, Ruina A, Cannon CE, Hui Chang Y, Coleman MJ (1999) A point-mass model of gibbon locomotion. J Exp Bio/ 202, 2609-2617.

Biewener AA (1998) Muscle-tendon stresses and elastic energy storage during locomotion in the horse. Comp Biochem Phys $B$ 120 (1), 73-87.

Carpenter CR (1976) Suspensory behavior of gibbons ( $H$. lar) - a photo essay. In Gibbon and Siamang: A Series of Volumes on the Lesser Apes, Vol. 4: Suspensory Behavior, Locomotion and other Behaviors of Captive Gibbons: Cognition (ed. Rumbaugh DM), pp. 1-20.Basel: Karger.
Cavagna GA, Heglund NC, Taylor CR (1977) Mechanical work in terrestrial locomotion - 2 basic mechanisms for minimizing energy-expenditure. Am J Physio/ 233 (5), R243-R261.

Chan LK (2007) Scapular position in primates. Folia Primatol 78, 19-35.

Chang YH, Bertram JEA, Ruina A (1997) A dynamic force and moment analysis system for brachiation. J Exp Biol 200, 30133020.

Chang YH, Bertram JEA, Lee DV (2000) External forces and torques generated by the brachiating white-handed gibbon (Hylobates lar). Am J Phys Anthropol 113, 201-216.

Cheng EJ, Scott SH (2000) Morphometry of Macaca mulatta forelimb I. Shoulder and elbow muscle and segmental inertial parameters. J Morphol 245, 206-224.

Fleagle JG (1974) The dynamics of the brachiating siamang (Symphalangus syndactylus). Nature 248, 259-260.

Fleagle JG (1976) Locomotion and posture of the Malayan siamang and implications for hominid evolution. Folia Primato/ 26, 245-269.

Fleagle JG (1979) Primate positional behavior and anatomy: naturalistic and experimental approaches. In Environment, Behavior, and Morphology: Dynamic Interactions in Primates (eds Morbeck M, Preuschoft H, Gomberg N), pp. 313-325. New York: Gustav Fisher.

Fleagle JG (1999) Locomotor adaptations. In Primate Adaptation and Evolution, pp. 297-306. NY: Elsevier Academic Press.

Gibbs S, Collard M, Wood B (2002) Soft-tissue anatomy of the extant hominoids: a review and phylogenetic analysis. $J$ Anat 200 (1), 3-49.

Gomes M, Ruina A (2005) A five-link 2D brachiating ape model with life-like zero-energy-cost motions. J Theor Biol 237, 265278.

Gray H (1918) Anatomy of the Human Body (ed. Lewis WH). Philadelphia: Lea \& Febiger.

Hill AV (1953) The mechanics of active muscle. Proc Roy Soc Lond (Biol) 141, 104-117.

Hollihn U (1984) Bimanual suspensory behavior: morphology, selective advantages and phylogeny. In The Lesser Apes: Evolutionary and Behavioral Biology (eds Preuschoft DH, Chivers DJ, Brockelman WY, Creel N), pp. 85-95. Edinburgh: Edinburgh University Press.

Howell AB, Straus WL Jr (1961) The muscular system. In Anatomy of the Rhesus Monkey (ed. Hartman CG), pp. 89-175. New York: Hafner.

Jungers WL, Stern JT (1980) Telemetered electromyography of forelimb muscle chains in gibbons (Hylobates lar). Science 208, 617-619.

Jungers WL, Stern JT (1981) Preliminary electromyographical analysis of brachiation in gibbon and spider monkey. Int J Primatol 2 (1), 19-33.

Ker R, Alexander RM, Bennet M (1988) Why are mammalian tendons so thick? J Zool Lond 216, 309-324.

Ker RF, Wang XT, Pike AVL (2000) Fatigue quality of mammalian tendons. J Exp Bio/ 203, 1317-1327.

Kimura K, Takai S (1970) On the musculature of the fore limb of the crab-eating monkey. Primates 11, 145-170.

Medler S (2002) Comparative trends in shortening velocity and force production in skeletal muscles. Am J Physiol-Reg / 283, R368-R378.

Mendez J, Keys A (1960) Density and composition of mammalian muscle. Metabolism 9, 184-188.

Miller RA (1932) Evolution of the pectoral girdle and forelimb in the primates. Am J Phys Anthropol 17 (1), 1-56. 
Miller RA (1952) The musculature of Pan paniscus. J Anat 91, 83-232. Napier JR, Napier PH (1967) A handbook of living primates. Morphology, Ecology and Behaviour of Non-Human Primates. London: Academic Press.

Payne R, Crompton RH, Isler K, et al. (2006) Morphological analysis of the hindlimbs in apes and humans. I. Muscle architecture. $J$ Anat 208, 709-724.

Preuschoft H, Demes B (1984) Biomechanics of brachiation. In The Lesser Apes: Evolutionary and Behavioral Biology (eds Preuschoft H, Chivers DJ, Brockelman WY, Creel N), pp. 96-118. Edinburgh: Edinburgh University Press.

Prime JM, Ford SM (2006) Hand manipulation skills of gibbons. Am J Phys Anthropol S42, 149-149.

Roberts TJ (2002) The integrated function of muscles and tendons during locomotion. Comp Biochem Phys A 133, 1087-1099.

Schultz AH (1973) The skeleton of the Hylobatidae and other observations on their morphology. In Gibbon and Siamang: $A$ Series of Volumes on the Lesser Apes, Vol. 4: Suspensory Behavior, Locomotion and Other Behaviors of Captive Gibbons: Cognition (ed. Rumbaugh DM), pp. 1-54. Basel: Karger.

Stern JT, Larson SG (2001) Telemetered EMG of the supinators and pronators of the forearm in gibbons and chimpanzees. Am J Phys Anthropol 115, 253-268.

Stern JT Jr, Wells JP, Jungers WL, Vangor AK, Fleagle JG (1980) An electromyographic study of the pectoralis major in atelines and hylobates, with special reference to the evolution of a pars clavicularis. Am J Phys Anthropol 52, 13-25.

Susman RL, Jungers WL, Stern JT Jr (1982) The functional morphology of the accessory interosseous muscle in the gibbon hand: determination of locomotor and manipulatory compromises. $J$ Anat 134, 111-120.

Swartz SM, Bertram JEA, Biewener AA (1989) Telemetered in vivo strain analysis of locomotor mechanics of brachiating gibbons. Nature 342, 270-272.

Swindler DR, Wood CD (1973) An Atlas of Primate Gross Anatomy. Seattle: University of Washington Press.
Takahashi LK (1990) Morphological basis of arm-swinging: multivariate analyses of the forelimbs of Hylobates and Ateles. Folia Primatol 54, 70-85.

Thorpe SKS, Crompton RH, Günther MM, Ker RF, Alexander RM (1999) Dimensions and moment arms of the hind- and forelimb muscles of common chimpanzees (Pan troglodytes). Am J Phys Anthropol 110, 179-199.

Turnquist JE, Schmitt D, Rose MD, Cant JGH (1999) Pendular motion in the brachiation of captive Lagothrix and Ateles. Am J Primatol 48, 263-281.

Tuttle RH (1972) Functional and evolutionary biology of hylobatid hands and feet. In Gibbon and Siamang: A Series of Volumes on the Lesser Apes, Vol. 4: Suspensory Behavior, Locomotion and Other Behaviors of Captive Gibbons: Cognition (ed. Rumbaugh DM), pp. 136-206. Basel: Karger.

Tuttle RH (1986) Suspensory behaviour. In Apes of the World. Their Social Behavior, Communication, Mentality and Ecology. Chap. 2. pp. 33-40. New Jersey: Noyes Park Ridge.

Usherwood JR, Bertram JEA (2003) Understanding brachiation: insight from a collisional perspective. J Exp Biol 206, 16311642.

Usherwood JR, Larson SG, Bertram JEA (2003) Mechanics of force and power production in unsteady ricochetal brachiation. Am J Phys Anthropol 120, 364-372.

Voisin JL (2006) Clavicle, a neglected bone: Morphology and relation to arm movements and shoulder architecture in primates. Anat Rec 288A, 944-953.

Wells JB (1965) Comparison of mechanical properties between slow and fast mammalian muscles. J Physiol 178, 252-269.

Youlatos D (2000) Functional anatomy of forelimb muscles in Guianan atelines (Platyrrhini: Primates). Annal Sci Nat 21 (4), 137-151.

Zajac FE (1992) How musculotendon architecture and joint geometry affect the capacity of muscles to move and exert force on objects: a review with application to arm and forearm tendon transfer design. J Hand Surg 17 (5), 799-804.

Appendix A Averaged and normalized (to average body mass of $7.7 \mathrm{~kg}$ ) data for each muscle and each of the four measured gibbon species

\begin{tabular}{|c|c|c|c|c|c|c|c|c|}
\hline \multirow[b]{2}{*}{ Muscle } & \multicolumn{4}{|l|}{ Lar } & \multicolumn{4}{|l|}{ Pileated } \\
\hline & Mass (g) & PCSA $\left(\mathrm{mm}^{2}\right)$ & $\mathrm{FL}(\mathrm{mm})$ & TL : MTU & Mass (g) & PCSA $\left(\mathrm{mm}^{2}\right)$ & $\mathrm{FL}(\mathrm{mm})$ & TL : MTU \\
\hline Pmaj & 49.82 & 392 & 107 & 0.28 & 60.12 & 562 & 102 & 0.17 \\
\hline Pmin & 5.15 & 60 & 58 & 0.27 & 5.06 & 55 & 86 & 0.19 \\
\hline LD & 59.00 & 368 & 149 & 0.25 & 66.95 & 493 & 129 & 0.21 \\
\hline Trap & 33.59 & 521 & 62 & & 26.44 & 357 & 70 & \\
\hline Serr & 19.43 & 209 & 90 & & 18.28 & 196 & 88 & \\
\hline $\mathrm{Rh}$ & 13.28 & 228 & 57 & & 13.37 & 248 & 51 & \\
\hline Rmin & 3.00 & & & & 3.57 & 72 & 47 & \\
\hline LS & 7.38 & 88 & 74 & & 4.25 & 47 & 96 & \\
\hline SPSA & 7.72 & & & & 6.55 & 139 & 45 & \\
\hline$D$ & 57.64 & 1352 & 37 & & 57.53 & 974 & 55 & 0.56 \\
\hline Tmaj & 20.23 & 224 & 87 & & 20.05 & 249 & 77 & \\
\hline Tmin & 4.74 & 124 & 37 & 0.25 & & & & \\
\hline SS & 11.79 & 300 & 30 & 0.51 & 15.50 & 361 & 38 & 0.56 \\
\hline IS & 15.56 & 328 & 41 & 0.60 & 17.14 & 355 & 41 & 0.63 \\
\hline SSc & 31.53 & 736 & 35 & 0.45 & 28.10 & 539 & 50 & 0.52 \\
\hline DET & 9.05 & 110 & 54 & 0.60 & 11.33 & 205 & 51 & \\
\hline$B$ & 66.42 & 581 & 95 & 0.35 & 71.55 & 794 & 85 & 0.61 \\
\hline
\end{tabular}


Appendix A (continued)

\begin{tabular}{|c|c|c|c|c|c|c|c|c|}
\hline \multirow[b]{2}{*}{ Muscle } & \multicolumn{4}{|l|}{ Lar } & \multicolumn{4}{|l|}{ Pileated } \\
\hline & Mass (g) & PCSA $\left(\mathrm{mm}^{2}\right)$ & $\mathrm{FL}(\mathrm{mm})$ & TL : MTU & Mass (g) & PCSA $\left(\mathrm{mm}^{2}\right)$ & $\mathrm{FL}(\mathrm{mm})$ & TL : MTU \\
\hline $\mathrm{CB}$ & 6.54 & 160 & 36 & 0.27 & 8.45 & 194 & 41 & \\
\hline Bra & 36.57 & 451 & 69 & 0.39 & 45.89 & 601 & 66 & 0.35 \\
\hline $\operatorname{Tr}$ & 51.06 & 911 & 47 & 0.65 & 43.19 & 833 & 49 & 0.69 \\
\hline BR & 9.72 & 75 & 107 & 0.46 & 13.95 & 154 & 81 & 0.44 \\
\hline ECRL & 4.59 & 72 & 51 & 0.82 & 5.08 & 76 & 50 & 0.81 \\
\hline ECRB & 5.11 & 117 & 34 & 0.84 & 5.47 & 126 & 35 & 0.82 \\
\hline FCR & 8.86 & 274 & 33 & 0.67 & 13.31 & 300 & 39 & 0.73 \\
\hline FCU & 5.95 & 152 & 32 & 0.84 & 9.06 & 265 & 31 & 0.83 \\
\hline Palm & 3.56 & 89 & 35 & 0.84 & 3.18 & 131 & 21 & 0.79 \\
\hline PT & 8.37 & 298 & 23 & 1.00 & 6.41 & 271 & 22 & 0.61 \\
\hline FDS 2 & 39.96 & 668 & 47 & 0.83 & 43.83 & 571 & 77 & \\
\hline FDS 3 & & & & 0.79 & & & & \\
\hline FDS 4 & & & & 0.87 & & & & \\
\hline FDS 5 & & & & 0.86 & & & & \\
\hline FDP 1 & 39.00 & 1015 & 36 & 0.88 & 43.51 & 919 & 45 & \\
\hline \multicolumn{9}{|l|}{ FDP 2} \\
\hline \multicolumn{9}{|l|}{ FDP 3} \\
\hline \multicolumn{9}{|l|}{ FDP 4} \\
\hline \multicolumn{9}{|l|}{ FDP 5} \\
\hline$P Q$ & 0.91 & & & & 1.23 & & & \\
\hline EDC & 9.70 & 190 & 41 & & 12.53 & 233 & 46 & \\
\hline EDB & 2.92 & 94 & 28 & & 2.69 & 75 & 31 & \\
\hline EDM & 0.52 & 13 & 54 & 0.83 & 0.93 & 35 & 23 & \\
\hline $\mathrm{ECU}$ & 4.21 & 108 & 27 & 0.83 & 4.23 & 79 & 41 & 0.85 \\
\hline Sup & 8.11 & 588 & 6 & & 7.42 & & & \\
\hline EPL & 1.45 & 54 & 27 & 0.88 & 1.72 & 54 & 27 & \\
\hline EPB & 2.33 & 121 & 24 & 0.77 & 1.67 & 60 & 21 & 0.91 \\
\hline \multirow[t]{2}{*}{ APL } & 5.64 & 167 & 25 & 0.89 & 3.35 & 88 & 31 & 0.92 \\
\hline & \multicolumn{4}{|l|}{ Moloch } & \multicolumn{4}{|l|}{ Siamang } \\
\hline Muscle & Mass (g) & PCSA $\left(\mathrm{mm}^{2}\right)$ & $\mathrm{FL}(\mathrm{mm})$ & TL : MTU & Mass (g) & $\mathrm{PCSA}\left(\mathrm{mm}^{2}\right)$ & $\mathrm{FL}(\mathrm{mm})$ & TL : MTU \\
\hline Pmaj & 41.88 & 341 & 116 & 0.27 & 43.04 & 443 & 94 & 0.30 \\
\hline Pmin & 5.05 & 63 & 73 & 0.26 & 5.43 & 83 & 62 & 0.28 \\
\hline LD & 49.32 & 360 & 128 & 0.23 & 65.39 & 433 & 147 & 0.31 \\
\hline Trap & 26.36 & 382 & 67 & & 27.95 & 461 & 58 & 0.18 \\
\hline Serr & 14.11 & 161 & 83 & & 20.15 & 199 & 99 & \\
\hline $\mathrm{Rh}$ & 10.85 & 207 & 50 & & 10.91 & 196 & 53 & \\
\hline \multicolumn{9}{|l|}{$\mathrm{Rmin}$} \\
\hline LS & 3.73 & 47 & 78 & & 4.46 & 47 & 90 & \\
\hline SPSA & 4.10 & 108 & 37 & & 6.07 & 122 & 48 & \\
\hline $\mathrm{D}$ & 43.28 & 818 & 54 & 0.68 & 59.66 & 1128 & 46 & 0.51 \\
\hline Tmaj & 14.43 & 278 & 50 & 0.35 & 18.72 & 253 & 70 & 0.36 \\
\hline Tmin & 4.73 & 122 & 35 & 0.51 & 5.19 & 104 & 43 & 0.35 \\
\hline SS & 9.76 & 376 & 22 & 0.45 & 10.48 & 285 & 34 & 0.55 \\
\hline IS & 13.09 & 336 & 34 & 0.64 & 16.68 & 401 & 37 & 0.65 \\
\hline SSc & 22.26 & 607 & 36 & 0.52 & 31.65 & 668 & 39 & 0.58 \\
\hline DET & 7.85 & 152 & 49 & & 10.04 & 135 & 73 & 0.69 \\
\hline$B$ & 52.55 & 476 & 94 & 0.55 & 55.68 & 525 & 97 & 0.38 \\
\hline $\mathrm{CB}$ & 5.03 & 112 & 39 & & 7.99 & 170 & 45 & 0.38 \\
\hline Bra & 31.80 & 571 & 64 & 0.35 & 50.79 & 618 & 79 & 0.42 \\
\hline $\mathrm{Tr}$ & 37.00 & 957 & 39 & 0.66 & 40.99 & 690 & 61 & 0.71 \\
\hline BR & 8.85 & 100 & 77 & 0.64 & 13.89 & 149 & 89 & 0.64 \\
\hline ECRL & 3.67 & 64 & 45 & 0.84 & 5.08 & 78 & 57 & 0.83 \\
\hline ECRB & 2.49 & 50 & 42 & 0.82 & 5.09 & 116 & 32 & 0.85 \\
\hline FCR & 7.41 & 180 & 34 & 0.68 & 10.55 & 276 & 35 & 0.71 \\
\hline
\end{tabular}


Appendix A (continued)

\begin{tabular}{|c|c|c|c|c|c|c|c|c|}
\hline \multirow[b]{2}{*}{ Muscle } & \multicolumn{4}{|l|}{ Moloch } & \multicolumn{4}{|l|}{ Siamang } \\
\hline & Mass (g) & PCSA $\left(\mathrm{mm}^{2}\right)$ & $\mathrm{FL}(\mathrm{mm})$ & TL : MTU & Mass (g) & PCSA $\left(\mathrm{mm}^{2}\right)$ & $\mathrm{FL}(\mathrm{mm})$ & TL : MTU \\
\hline $\mathrm{FCU}$ & 5.69 & 186 & 28 & 0.80 & 7.03 & 233 & 28 & 0.86 \\
\hline Palm & 2.74 & 72 & 33 & 0.84 & 2.80 & 73 & 30 & 0.85 \\
\hline PT & 6.59 & 225 & 25 & 0.59 & 7.76 & 339 & 20 & 0.56 \\
\hline FDS 2 & 45.76 & 893 & 42 & & 37.41 & 833 & 38 & 0.84 \\
\hline FDS 3 & & & & & & & & 0.86 \\
\hline FDS 4 & & & & & & & & 0.86 \\
\hline FDS 5 & & & & & & & & 0.84 \\
\hline FDP 1 & 30.92 & 598 & 41 & & 37.19 & 745 & 42 & 0.81 \\
\hline FDP 2 & & & & & & & & 0.98 \\
\hline FDP 3 & & & & & & & & 0.82 \\
\hline FDP 4 & & & & & & & & 0.73 \\
\hline FDP 5 & & & & & & & & 0.83 \\
\hline$P Q$ & 1.44 & & & 0.39 & 1.17 & 82 & 15 & \\
\hline EDC & 6.71 & 203 & 27 & & 9.74 & 156 & 42 & 0.78 \\
\hline EDB & 2.14 & 69 & 27 & & 3.13 & 85 & 28 & 0.85 \\
\hline EDM & 0.42 & 19 & 19 & & 1.16 & 26 & 38 & 0.82 \\
\hline ECU & 2.66 & 102 & 20 & 0.84 & 3.38 & 87 & 29 & 0.84 \\
\hline Sup & 7.45 & 264 & 26 & & 8.10 & 290 & 24 & 0.64 \\
\hline EPL & 1.22 & 30 & 31 & & 1.34 & 37 & 28 & 0.86 \\
\hline EPB & 1.27 & 44 & 25 & 0.73 & 1.58 & 59 & 27 & 0.78 \\
\hline APL & 3.23 & 110 & 27 & 0.90 & 4.94 & 146 & 25 & 0.84 \\
\hline
\end{tabular}

Appendix B Overview of dissected muscles with origin and insertion

\begin{tabular}{|c|c|c|c|}
\hline Muscle & Species & Origin & Insertion \\
\hline \multirow[t]{6}{*}{ Pectoralis major } & Gibbons & $\begin{array}{l}\text { Ribs } 1-6 \text {, lateral half of clavicle, small part of } \\
\text { sternum }\end{array}$ & $\begin{array}{l}\text { With broad tendon (ca. } 4 \mathrm{~cm} \text { ), to } \\
\text { bicipital groove running over biceps }\end{array}$ \\
\hline & & Var lar: lateral $2 / 3$ rd of clavicle & LH tendon \\
\hline & & & Var S3 and lar: second slip attaches to \\
\hline & & & biceps SH tendon; fusion with deltoid \\
\hline & Bonobo & Idem gibbon but ribs $1-7$ & Greater tubercle of humerus \\
\hline & Atelines & Idem gibbon but of clavicle & Idem gibbon \\
\hline \multirow[t]{3}{*}{ Pectoralis minor } & Gibbons & Lateral part ribs 2, 3 and 4 & Coracoid process of scapula \\
\hline & & Var lar: ribs $2-5$ & $\begin{array}{l}\text { Var S3 and lar: also lateral part of } \\
\text { clavicle }\end{array}$ \\
\hline & Bonobo & Idem gibbon & Idem gibbon \\
\hline \multirow[t]{2}{*}{ Trapezius } & Gibbons & $\begin{array}{l}\text { Cervical and thoracic vertebrae (spinous } \\
\text { processes) }\end{array}$ & $\begin{array}{l}\text { Lateral third of clavicle, scapular } \\
\text { spine, acromion }\end{array}$ \\
\hline & Bonobo & Idem gibbon & Idem gibbon \\
\hline \multirow[t]{4}{*}{ Latissimus dorsi } & Gibbons & $\begin{array}{l}\text { Lower } 6 \text { thoracic vertebrae, iliac crest, lower } 4 \\
\text { ribs }\end{array}$ & $\begin{array}{l}\text { With broad tendon to bicipital } \\
\text { groove }\end{array}$ \\
\hline & & Var lar: iliac crest not in all specimen & $\begin{array}{l}\text { Var lar: Tmaj fused with LD at } \\
\text { insertion }\end{array}$ \\
\hline & Bonobo & $\begin{array}{l}\text { Lower } 5 \text { thoracic vertebrae, lumbar and sacral } \\
\text { vertebra, iliac crest and lower } 5 \text { ribs }\end{array}$ & Idem gibbon \\
\hline & Atelines & Idem with some variation depending on species & Idem gibbon \\
\hline \multirow[t]{3}{*}{ Subclavius } & Gibbons & Cartilage of 1st rib & Dorsolateral part clavicle \\
\hline & & Var S3: 1st and 2nd rib; var lar: 2nd and 3rd rib & \\
\hline & Bonobo & Idem gibbon & Idem gibbon \\
\hline \multirow[t]{2}{*}{ Serratus anterior } & Gibbons & From 2 nd to 10 th ribs & $\begin{array}{l}\text { Medial border and inferior angle of } \\
\text { scapula }\end{array}$ \\
\hline & Bonobo & From 1st to 10 th ribs & $\begin{array}{l}\text { Superior angle and vertebral border } \\
\text { and inferior angle }\end{array}$ \\
\hline Pars superior of & Gibbons & Superior angle and medial border of scapula & $\begin{array}{l}\text { Rib 2-3 } \\
\text { Var lar. ribs 1-3 }\end{array}$ \\
\hline
\end{tabular}


Appendix B (continued)

\begin{tabular}{|c|c|c|c|}
\hline Muscle & Species & Origin & Insertion \\
\hline \multirow[t]{4}{*}{ Rhomboid } & Gibbons & Spinous processes of T2-T5 & Medial border and inferior angle of \\
\hline & & Var lar: T1-T5 & scapula \\
\hline & & & Var S1: also scapular spine \\
\hline & Bonobo & $\mathrm{C} 3$ to $\mathrm{T} 6$ & Idem gibbon \\
\hline \multirow[t]{2}{*}{ Levator scapulae } & Gibbons & Transverse processes of $\mathrm{C} 1-4$ & Superior angle of scapula \\
\hline & Bonobo & Idem gibbon & Idem gibbon \\
\hline \multirow[t]{5}{*}{ Deltoid } & Gibbons & $\begin{array}{l}\text { Lateral 2/3 of scapular spine, acromion process, } \\
\text { lateral third of clavicle }\end{array}$ & Lateral border of proximal humerus \\
\hline & & Var S3, S4 and lar: aponeurosis covers IS & \\
\hline & & Var lar: lateral $1 / 2$ of scapular spine & \\
\hline & Bonobo & Idem gibbon & Idem gibbon \\
\hline & Atelines & Idem gibbon & Idem gibbon \\
\hline \multirow[t]{3}{*}{ Teres major } & Gibbons & Inferior angle of scapula & Bicipital groove of humerus var \$4 \\
\hline & & Var lar: also lower third lateral border scapula & and lar: on tendon of LD \\
\hline & Bonobo & $\begin{array}{l}\text { Idem gibbon plus lower half of axilliary border } \\
\text { scapula }\end{array}$ & Lesser tubercle of humerus \\
\hline \multirow[t]{3}{*}{ Teres minor } & Gibbons & Lower lateral border of scapula & Greater tubercle of humerus (post- \\
\hline & & Var lar: middle of lateral border of scapula & lateral neck) \\
\hline & Bonobo & Axilliary border & Idem gibbon \\
\hline \multirow[t]{3}{*}{ Subscapularis } & Gibbons & Subscapular fossa & Lesser tubercle of humerus \\
\hline & & Var S1: also lower border scapula & $\begin{array}{l}\text { Var } \$ 1 \text { and lar: with tendon to } \\
\text { humerus head, with muscle fibres to } \\
\text { humerus neck }\end{array}$ \\
\hline & Bonobo & Idem gibbon & Idem gibbon \\
\hline \multirow[t]{3}{*}{ Supraspinatus } & Gibbons & Supraspinous fossa & $\begin{array}{l}\text { Superior part of greater tubercle of } \\
\text { humerus }\end{array}$ \\
\hline & Bonobo & Idem gibbon & Idem gibbon \\
\hline & Atelines & Idem gibbon & Idem gibbon \\
\hline \multirow[t]{2}{*}{ Infraspinatus } & Gibbons & Infraspinous fossa & $\begin{array}{l}\text { Middle part of greater tubercle of } \\
\text { humerus }\end{array}$ \\
\hline & Bonobo & Idem gibbon & Idem gibbon \\
\hline \multirow[t]{4}{*}{ Dorsoepitrochlearis } & Gibbons & From LD tendon, near insertion & $\begin{array}{l}\text { Fused with head of biceps } \mathrm{SH} \text {, thin } \\
\text { tendon-like aponeurosis to medial } \\
\text { condyle }\end{array}$ \\
\hline & Crab-eating monkey & Idem gibbon & Idem gibbon \\
\hline & Bonobo & Idem gibbon & Idem gibbon \\
\hline & Atelines & Idem gibbon & Idem gibbon \\
\hline \multirow[t]{3}{*}{ Coracobrachialis } & Gibbons & Coracoid process of scapula & $\begin{array}{l}\text { Proximal third of medial surface of } \\
\text { humerus }\end{array}$ \\
\hline & Crab-eating monkey & 2 parts: profundus and medial & Middle of humerus \\
\hline & Bonobo & Idem gibbon & Middle of humerus \\
\hline \multirow[t]{6}{*}{ Triceps } & Gibbons & $\begin{array}{l}\text { LH: superior lateral border scapula } \\
\text { (infraglenoid) }\end{array}$ & Olecranon process of ulna \\
\hline & & LatH: prox-post part of humerus & Var S1 and lar: part of tendon of \\
\hline & & $\mathrm{MH}$ : post and middle part of humerus (sulcus $\mathrm{n}$. & origin runs over aponeurosis at \\
\hline & & radialis between LatH and $\mathrm{MH}$ ) & insertion Tmaj \\
\hline & Crab-eatıng monkey & Idem gibbon & Idem gibbon \\
\hline & Bonobo & Idem gibbon & Idem gibbon \\
\hline \multirow{5}{*}{ Biceps } & Gibbons & $\begin{array}{l}\text { LH: supraglenoid tubercle } \\
\text { SH: lesser tubercle of humerus }\end{array}$ & $\begin{array}{l}\text { Tendon to radial tuberosity, muscle } \\
\text { fibres }(\mathrm{SH}) \text { to superficial flexors and }\end{array}$ \\
\hline & & $\begin{array}{l}\text { Var S1: not clearly 2-headed, only insertion on } \\
\text { lesser tubercle found }\end{array}$ & fascia \\
\hline & Crab-eating monkey & SH: processus coracoideus of scapula & Idem gibbon \\
\hline & Bonobo & SH: coracoid & Idem gibbon \\
\hline & Atelines & SH: coracoid & Idem gibbon \\
\hline Brachialis & Gibbons & $\begin{array}{l}\text { Distal } 1 / 2 \text { of anterior surface of humerus } \\
\operatorname{Var} S 1 \text { : distal } 2 / 3 \text { of anterior surface of humerus }\end{array}$ & $\begin{array}{l}\text { Proximal part of ulna }(2 \mathrm{~cm} \rightarrow 3.5 \mathrm{~cm} \text {; } \\
\text { tuberositas ulnae) }\end{array}$ \\
\hline
\end{tabular}


Appendix B (continued)

\begin{tabular}{lll}
\hline Muscle & Species & Origin \\
\hline & Crab-eating monkey & Idem gibbon \\
& Bonobo & Idem gibbon \\
& Atelines & Idem gibbon \\
Brachioradialis & Gibbons & Lateral supracondylar ridge
\end{tabular}

\begin{tabular}{|c|c|c|}
\hline & Crab-eating monkey & Idem gibbon \\
\hline & Bonobo & Idem gibbon \\
\hline \multirow[t]{3}{*}{ Palmaris } & Gibbons & Medial epicondyle of humerus \\
\hline & Crab-eating monkey & Idem gibbon \\
\hline & Bonobo & Idem gibbon \\
\hline \multirow{4}{*}{$\begin{array}{l}\text { Extensor digitorum } \\
\text { communis }\end{array}$} & Gibbons & Lateral epicondyle of humerus \\
\hline & & Var S1: tendon at origin \\
\hline & Crab-eating monkey & Idem gibbon and fascia antebrachia \\
\hline & Bonobo & Idem gibbon \\
\hline \multirow[t]{3}{*}{ Extensor carpi ulnaris } & Gibbons & $\begin{array}{l}\text { Proximal third of ulna and lateral epicondyle } \\
\text { humerus }\end{array}$ \\
\hline & Crab-eating monkey & Lateral epicondyle \\
\hline & Bonobo & Idem gibbon \\
\hline \multirow{3}{*}{$\begin{array}{l}\text { Extensor carpi radialis } \\
\text { longus }\end{array}$} & Gibbons & Lateral supracondylar ridge humerus \\
\hline & Crab-eating monkey & Idem gibbon \\
\hline & Bonobo & Idem gibbon \\
\hline \multirow{4}{*}{$\begin{array}{l}\text { Extensor carpi radialis } \\
\text { brevis }\end{array}$} & Gibbons & Lateral epicondyle humerus \\
\hline & & Var S1: also belly EDC \\
\hline & Crab-eating monkey & Idem gibbon \\
\hline & Bonobo & Idem gibbon \\
\hline \multirow[t]{2}{*}{ Extensor digiti minimi } & Gibbons & Lateral epicondyle of humerus \\
\hline & & Var S1and lar: also middle part ulna \\
\hline
\end{tabular}

Extensor digitorum Gibbons brevis
Distal 2/3 of ulna

Var lar: middle of ulna

\begin{tabular}{|c|c|c|}
\hline \multirow{3}{*}{$\begin{array}{l}\text { Extensor pollicis } \\
\text { longus }\end{array}$} & Gibbons & Proximal $1 / 4$ of ulna \\
\hline & Crab-eating monkey & Idem gibbon \\
\hline & Bonobo & Middle $1 / 3$ rd ulna \\
\hline $\begin{array}{l}\text { Extensor pollicis } \\
\text { brevis }\end{array}$ & Gibbons & $\begin{array}{l}\text { Proximal medial part of radius and } \mathrm{I} / \mathrm{O} \\
\text { membrane } \\
\text { Var } \mathrm{S} 1: \text { proximal } 1 / 2 \text { and also prox ulna } \\
\text { Var lar: middle } 1 / 3\end{array}$ \\
\hline & Bonobo & Absent \\
\hline $\begin{array}{l}\text { Abductor pollicis } \\
\text { longus }\end{array}$ & Gibbons & $\begin{array}{l}\text { Proximal } 1 / 3 \text { of ulna and radius, prox to EPB } \\
\text { Var } \$ 1 \text { : proximal half of ulna and radius }\end{array}$ \\
\hline
\end{tabular}

Insertion

Idem gibbon

Idem gibbon

Ulnar shaft

Middle of radius

Var S1 and S3: radius head (styloid

process)

Var S4: distal part radius

Distal part radius

Distal part radius

Palmar aponeurosis

Idem gibbon

Transverse carpal ligament

2nd phalanx of D2-4

Var S1: tendons all fused

Var lar: D2-5

2nd and 3rd phalanges D2-5

2nd and 3rd phalanges D2-5

Lateral side base 5th metacarpal

Idem gibbon

Idem gibbon

Base of 1st and 2nd metacarpa

Var lar: 2 tendons at insertion

2nd metacarpal

2nd metacarpal

Base of 2nd and 3rd metacarpal

Var S4: only 2nd; var lar: only 3ro

3rd metacarpal

3rd metacarpal

Dorsal aponeurosis (middle phalanx)

of D5

Var S1 tendon fused with ECU tendon

2 tendons at insertion (fused)

Var lar: fused with EDC but tendon

runs in own tendon sheet

Splitting at wrist into two

Part 1: base prox phalanx of D2

Part 2: to base of prox phalanx of D3/

D4

Var S1 and lar: base prox phalang D2-

4 and extensor sheet phalanges

(sometimes only D2-3)

Var S2: tendon fused with tendon

EDC

Terminal phalanx of pollex (dorsal

side)

Idem gibbon

Idem gibbon

Dorsal side 1st metacarpal

Var S1: scaphoid-trapezium (= APL?)

Var S3 and lar: med part base MC1; also in lar fused with APL

Medial side base of MC1

Var S2: 1 muscle belly with 2 tendons (1 very thin) $\rightarrow 2$ insertions on same bone: trapezium

Var S: trapezium (only 1 tendon) 
Appendix B (continued)

\begin{tabular}{|c|c|c|c|}
\hline Muscle & Species & Origin & Insertion \\
\hline & Crab-eating monkey & $\begin{array}{l}\text { Middle } 3 / 5 \text { ulna, proximal } 2 / 3 \text { radius and } 1 / O \\
\text { membrane }\end{array}$ & Metacarpal and sesamoid bone \\
\hline & Bonobo & $\begin{array}{l}\text { Middle } 3 / 5 \text { ulna, proximal } 2 / 3 \text { radius and } 1 / O \\
\text { membrane }\end{array}$ & Idem gibbon and trapezium \\
\hline \multirow{8}{*}{$\begin{array}{l}\text { Flexor digitorum } \\
\text { superficialis }\end{array}$} & Gibbons & D2: proximal part of ulna & Four tendons to both sides of middle \\
\hline & & D3: lateral border of radius & phalanges D2-5 \\
\hline & & D4: medial epicondyle of humerus & \\
\hline & & D5: proximal half of ulna & \\
\hline & & $\begin{array}{l}\text { Var S1: D2: prox } 1 / 2 \text { ulna and heads D4 and D5 } \\
\text { fused }\end{array}$ & \\
\hline & Crab-eating monkey & Medial epicondyl humerus & Idem gibbon \\
\hline & Bonobo & D2: coronoid & Idem gibbon \\
\hline & Atelines & $\begin{array}{l}2 \text { distinct heads both from medial humeral } \\
\text { epicondyle }\end{array}$ & $\begin{array}{l}\text { Five tendons to both sides of middle } \\
\text { phalanges D1-5 }\end{array}$ \\
\hline \multirow{10}{*}{$\begin{array}{l}\text { Flexor digitorum } \\
\text { profundus }\end{array}$} & Gibbons & Medial, middle $2 / 3$ surface of radius, prox ulna, & Base distal phalanges D1-5 \\
\hline & & anterior surface and lateral border of ulna & Var S1: D1-2 and D4-5 tendons fused, \\
\hline & & Var $\mathrm{S} 1:$ middle $1 / 3$ radius and $\mathrm{I} / \mathrm{O}$ membrane & D4-5 and D2-3 fused MB, D1 has \\
\hline & & Var lar: medial epicondyle & separate MB \\
\hline & & & Var S3: D1-2 share MB + tendon, D3 \\
\hline & & & biggest tendon + separate MB, D4 \\
\hline & & & $\begin{array}{l}\text { has multiple small tendons and } \\
\text { shares MB with D5 }\end{array}$ \\
\hline & Crab-eating monkey & Idem gibbon & Idem gibbon \\
\hline & Bonobo & Idem gibbon & Idem gibbon \\
\hline & Atelines & $\begin{array}{l}\text { Idem gibbon and medial epicondyle but ateles } \\
\text { additional humeral head }\end{array}$ & Idem gibbon \\
\hline \multirow[t]{3}{*}{ Flexor carpi radialis } & Gibbons & $\begin{array}{l}\text { Medial epicondyle humerus idem } \\
\text { Var lar: also from PT }\end{array}$ & Palmar side base of $\mathrm{MC2}$ \\
\hline & Crab-eating monkey & Idem gibbon & Idem gibbon \\
\hline & Bonobo & Idem gibbon & Idem gibbon \\
\hline \multirow[t]{3}{*}{ Flexor carpi ulnaris } & Gibbons & Proximal $2 / 3$ ulna with oleocranon process & Pisiform bone \\
\hline & Crab-eating monkey & $\begin{array}{l}2 \text { heads: one same as gibbon and one medial } \\
\text { epicondyle humerus }\end{array}$ & Idem gibbon \\
\hline & Bonobo & Medial epicondyle and lateral ulna & $\begin{array}{l}\text { Idem gibbon and base of } 5 \text { th } \\
\text { metacarpal }\end{array}$ \\
\hline \multirow[t]{5}{*}{ Supinator } & Gibbons & Lateral epicondyle of humerus & Proximal posterior side radius \\
\hline & & Var lar: proximal $1 / 3$ radius and radial tuberosity & Var lar: proximal side ulna \\
\hline & Crab-eating monkey & Idem gibbon & Prox ulna \\
\hline & Bonobo & Idem gibbon & Idem gibbon \\
\hline & Atelines & Idem gibbon & Idem gibbon \\
\hline \multirow[t]{4}{*}{ Pronator teres } & Gibbons & Medial epicondyle of humerus & $\begin{array}{l}\text { Proximal lateral border of radius, } \\
\text { often fused with FDS }\end{array}$ \\
\hline & Crab-eating monkey & Idem gibbon & Idem gibbon \\
\hline & Bonobo & Idem gibbon plus coronoid processus & Middle third of radius \\
\hline & Atelines & Idem gibbon & Radial shaft \\
\hline \multirow[t]{4}{*}{ Pronator quadratus } & Gibbons & Anterior distal $1 / 4$ of ulna (I/O side) & Anterior distal $1 / 4$ of radius (I/O side) \\
\hline & Crab-eating monkey & Idem gibbon & Idem gibbon \\
\hline & Bonobo & Idem gibbon & Idem gibbon \\
\hline & Atelines & Ulnar shaft & Radial shaft \\
\hline
\end{tabular}

Variations in muscle course found in separate individuals or species are indicated (var = variation; $\mathrm{LH}=$ long head; $\mathrm{SH}=$ short head; latH = lateral head; $\mathrm{MH}=$ medial head; $\mathrm{I} / \mathrm{O}=$ interosseous; $\mathrm{MC}=$ metacarpals; $\mathrm{D}=$ digits; $\mathrm{T}=$ thoracic; $\mathrm{C}=$ cervical; $\mathrm{MB}=$ muscle belly) (crab-eating monkey: Kimura \& Takai, 1970; bonobo: Miller, 1952; atelines: Youlatos, 2000). 